\title{
Surface Modification by Ion Implantation to Improve the Oxidation Resistance of Materials for High Temperature Technology
}

\author{
Hans-Eberhard Zschau and Michael Schütze \\ Dechema e. V., Karl-Winnacker-Institut, Frankfurt am Main
}

Germany

\section{Introduction}

The intermetallic Titaniumaluminides are expected to have a high potential as material in high temperature technology. Their high specific strength at temperatures above $700^{\circ} \mathrm{C}$ offers the possibility for manufacturing components of aerospace and automotive industries. With a specific weight of $50 \%$ of that of the widely used Ni-based superalloys TiAl is very suitable for fast rotating parts like turbine blades in aircraft engines and land based power stations, exhaust valves or turbocharger rotors. Thus lower mechanical stresses and a reduced fuel consumption are expected. In contrast to these benefits TiAl shows insufficient oxidation resistance at temperatures above $750^{\circ} \mathrm{C}$ (Rahmel et al., 1995). To reach higher service temperatures a protective alumina scale would be needed. A surface modification avoids any detrimental influence on the excellent mechanical properties of the material. By using the "halogen effect" a dense protective alumina scale was formed after doping the metal surface with small amounts of chlorine (Kumagai et al., 1996; Schütze \& Hald, 1997; Donchev et al., 2003; Schumacher et al., 1999a; Schumacher et al., 1999b; Hornauer et al., 1999). The halogen effect can be explained by a thermodynamic model assuming the preferred formation and transport of volatile Alhalides through pores and microcracks within the metal/oxide interface and their conversion into alumina, forming a protective oxide scale on the surface (Donchev et al., 2003). However the alumina scale fails during thermocyclic loading of Cl-implanted TiAlsamples. Based on this model comprehensive calculations have been performed for fluorine and TiAl predicting a positive effect. The results of thermodynamical calculations have to be transformed into F-concentrations. The beam line ion implantation is chosen as a method of F-application because of its accuracy and reproducibility. By varying the implantation parameters optimal conditions have to be determined to meet the region of F-amounts necessary for a positive F-effect. The implanted F-depth profiles can be verified by the non-destructive ion beam analysis method PIGE (Proton Induced Gamma-ray Emission). The alumina scale formed via the F-effect is adherent even under thermocyclic conditions. However technical use is only possible if the fluorine effect can be stabilized for a time of at least 1000 hours. Hence after the alumina scale formation the stability of oxidation protection depends on the behaviour of the implanted fluorine vs. 
oxidation time. This work is dedicated to the role of fundamental material parameters related to the stability of the fluorine effect at TiAl.

Ni-base superalloys with Al-contents of less than $10 \mathrm{wt} \%$ are widely used in high temperature technology due to their superior mechanical properties. In contrast to this their oxidation resistance may be insufficient at temperatures above $950^{\circ} \mathrm{C}$. Oxidation of these $\mathrm{Ni}$ base alloys does not form a pure protective continuous alumina scale on the surface, but rather a complex layer structure of spinel phases and a significant amount of internal oxidation is formed (Litz et al., 1989). However the formation of a dense continuous alumina scale without significant internal oxidation would theoretically be possible, if a ",critical“ Alconcentration $\mathrm{N}_{\mathrm{c}}$ is realized. In this work a new concept for the formation of a protective alumina scale on the surface is presented. The change from a non-protective discontinuous internal to a continuous dense protective external alumina scale can be achieved by an "artificial" increase of the Al-activity on the surface. This can be realized via the halogen effect at Ni-based alloys. Thermodynamical calculations show the existence of a region for a positive fluorine effect for the Ni-based alloys, e. g. IN738 and IN939 at temperatures between $900-1200^{\circ} \mathrm{C}$. These results have to be transformed into fluorine concentrations by a screening using fluorine ion implantation.

\section{Materials and methods}

Cast $\gamma$-TiAl (Ti-50 at.\% Al) and the technical $\gamma$-Met alloy (46.6 at.\% $\mathrm{Al}$ ) manufactured by powder metallurgy were prepared as coupons of size $8^{*} 8^{*} 1 \mathrm{~mm}^{3}$ and polished with $\mathrm{SiC}$ paper down to 4000 and 1200 grit resp. Microstructural investigations showed minor amounts of the $\alpha_{2}-\mathrm{Ti}_{3} \mathrm{Al}$ phase (lamellar structure) within the $\gamma$-TiAl phase. For the Fimplantation fluences between $1 \times 10^{16}$ and $4 \times 10^{17} \mathrm{~F} \mathrm{~cm}^{-2}$ were used. The ion energy of $20 \mathrm{keV}$ corresponds to a mean projected range of $35 \mathrm{~nm}$ for F-ions in TiAl. The coupons of Ni-based alloy IN738 with a size of $10^{*} 10^{*} 1 \mathrm{~mm}^{3}$ were polished down to 4000 grit. Fluorine ions with fluences between $1 \times 10^{16}$ and $4 \times 10^{17} \mathrm{~F} \mathrm{~cm}^{-2}$ were chosen for the implantation. With an energy of $38 \mathrm{keV}$ a projected mean range of $35 \mathrm{~nm}$ in IN738 has been achieved.

All beam line implantations were carried out at the $60 \mathrm{kV}$ implanter of the Institute of Nuclear Physics (IKF) of the Johann Wolfgang Goethe - University in Frankfurt/Main using $\mathrm{CF}_{4}$ in the gas source. The fluorine concentration depth profiles were determined by using the non-destructive PIGE-technique (Tesmer \& Nastasi, 1995). The PIGE measurements were performed at the $2.5 \mathrm{MV}$ Van de Graaff accelerator of the IKF using the nuclear reaction ${ }^{19} \mathrm{~F}\left(\mathrm{p}, \mathrm{a}_{\gamma}\right)^{16} \mathrm{O}$ at resonance energies of $\mathrm{E}_{\mathrm{p}}=340 \mathrm{keV}$ and $484 \mathrm{keV}$, resp., and detecting the high energetic $\gamma$-rays (5-6 MeV) with a 10 inch NaI-detector. The information depth of the PIGE depth profiling is within $1.4-1.5 \mu \mathrm{m}$, whereas the depth resolution near the surface is about $10 \mathrm{~nm}$. The non-destructive RBS (ㅈutherford Backscattering Spectrometry) using He-ions of 2 and $3.53 \mathrm{MeV}$ enables the determination of $\mathrm{O}, \mathrm{Al}$ and Ti-depth profiles simultaneously. For the TGA (Thermo-Gravimetric Analysis) mesurements both sides and all edges of the specimens were implanted.

The TiAl-samples were oxidized isothermally and thermocyclically (cycles of $1 \mathrm{~h}$ and $24 \mathrm{~h}$ ) in a furnace at $900^{\circ} \mathrm{C}$ and $1000^{\circ} \mathrm{C}$ in lab air.

The Ni-alloy samples were oxidized isothermally between $12 \mathrm{~h}$ and $1000 \mathrm{~h}$ at $1050^{\circ} \mathrm{C}$. Finally all samples were inspected by metallographic methods and SEM. 


\section{Surface modification of TiAl by fluorine ion implantation}

\subsection{Principles of the halogen effect for TiAl}

$\mathrm{\gamma}$-TiAl with an $\mathrm{Al}$-content between 44 and 50 at.\% has a very promising prospect in high temperature application (fig. 1). In contrast to the good mechanical properties at temperatures above $750^{\circ} \mathrm{C}$ the TiAl-surface is covered with a porous titania scale on top and a porous scale of fast growing mixed titania and alumina underneath (fig. 2). This scale does not hinder the further inward diffusion of oxygen and nitrogen leading to the continuous formation of this mixed oxide scale. Already after $12 \mathrm{~h}$ at $900^{\circ} \mathrm{C}$ the scale thickness exceeds $10 \mu \mathrm{m}$. Finally, these processes will lead to a rapid destruction of the alloy (fig. 2). The insufficient oxidation resistance of TiAl can be improved by using the halogen effect. The principles of the halogen effect at TiAl are illustrated in fig. 3 for fluorine.

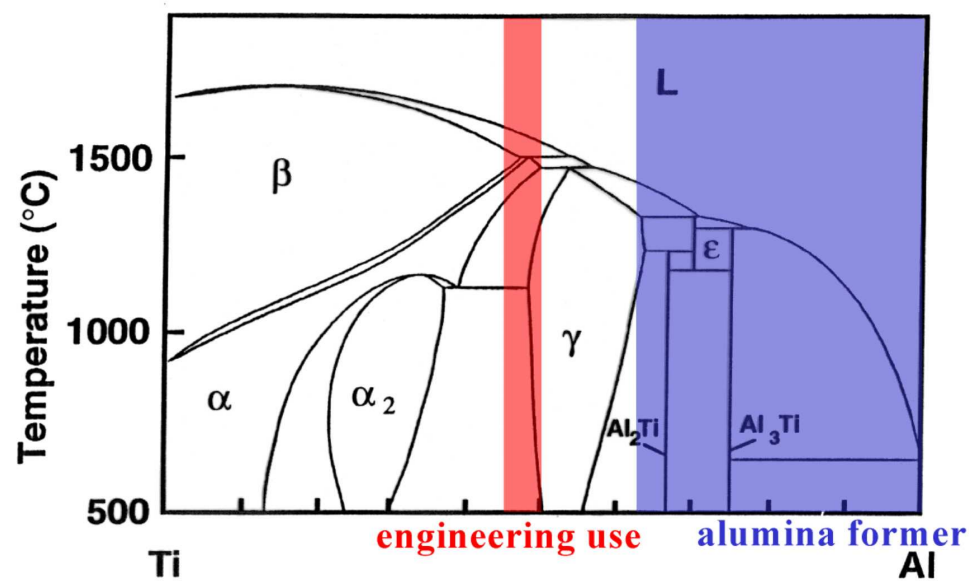

Fig. 1. Phase diagram of TiAl (Calphad).
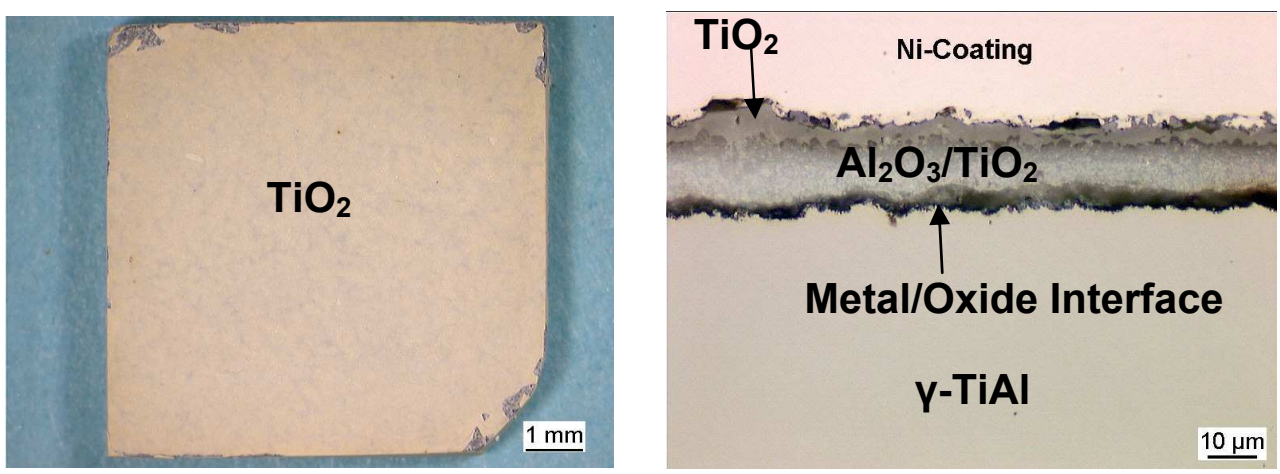

Fig. 2. Untreated $\gamma$-TiAl after oxidation $\left(12 \mathrm{~h} / 900^{\circ} \mathrm{C} /\right.$ air $)$. Left image: A brittle white $\mathrm{TiO}_{2-}$ layer is visible on top. Right image: Metallographic cross-section. $\mathrm{A} \mathrm{TiO}_{2}$-top scale and underlying mixed $\mathrm{Al}_{2} \mathrm{O}_{3} / \mathrm{TiO}_{2}$-scale covers the surface. The Ni-coating comes from the metallographic preparation. 

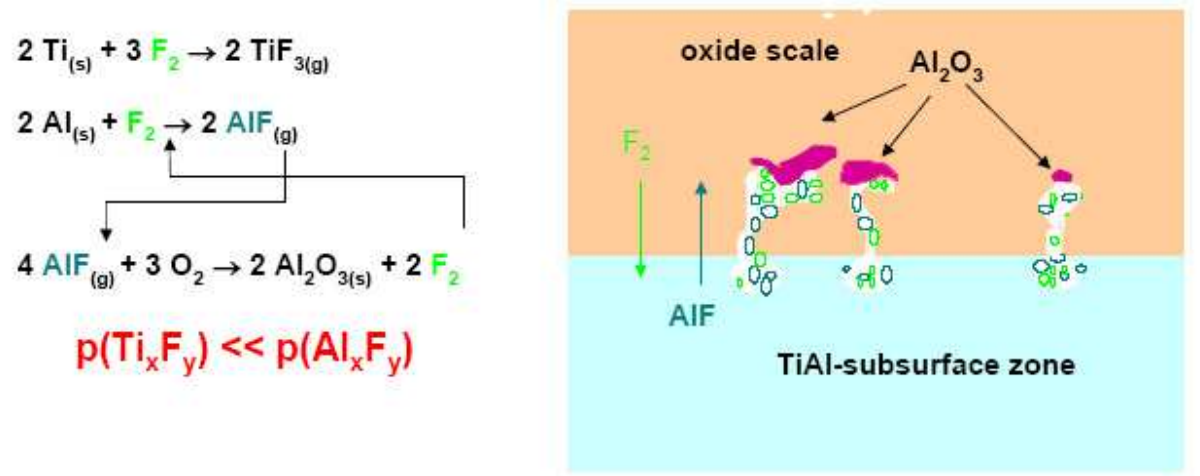

Fig. 3. Principle reactions of the F-effect at TiAl (Donchev et al., 2003).

A preferred formation of Al-fluorides occurs, if their partial pressure is significantly higher than that of the Ti-fluorides formed. Thus, the Al-fluorides migrate to the surface where they disintegrate to $\mathrm{F}_{2}$ and $\mathrm{Al}$, which is oxidized to alumina due to the increasing oxygen partial pressure. The free gaseous fluorine is able to return into the subsurface zone to form Alfluorides again. This cycle process leads to the formation of a thin protective $\mathrm{Al}_{2} \mathrm{O}_{3}-$ scale. Thermodynamic calculations for TiAl with Al-amounts between $40-50$ at. $\%$ using the software FactSage (FactSage) show the existence of a region with significantly higher partial pressures of Al-fluorides compared to Ti-fluorides as depicted in fig. 4 (Masset \& Schütze, 2008). In this case a AIF-partial pressure of at least $10^{-8}$ bar is required to form and to transport a significant amount of $\mathrm{Al}$ to the surface (Fergus, 2002). By increasing the total F-partial pressure to $\mathrm{p}(\mathrm{F})_{\min }$ at first the partial pressure of AlF meets this condition and the window for the F-effect is open. If the total F-partial pressure exceeds the value of $p(F)_{\max }$ the partial pressures of competing Tifluorides become significant. Thus the window for the F-effect is closed. The existence of a window for the F-effect at TiAl was found for temperatures between 900 and $1200^{\circ} \mathrm{C}$ defining a corridor for the F-effect for this temperature range (Donchev et al., 2003).

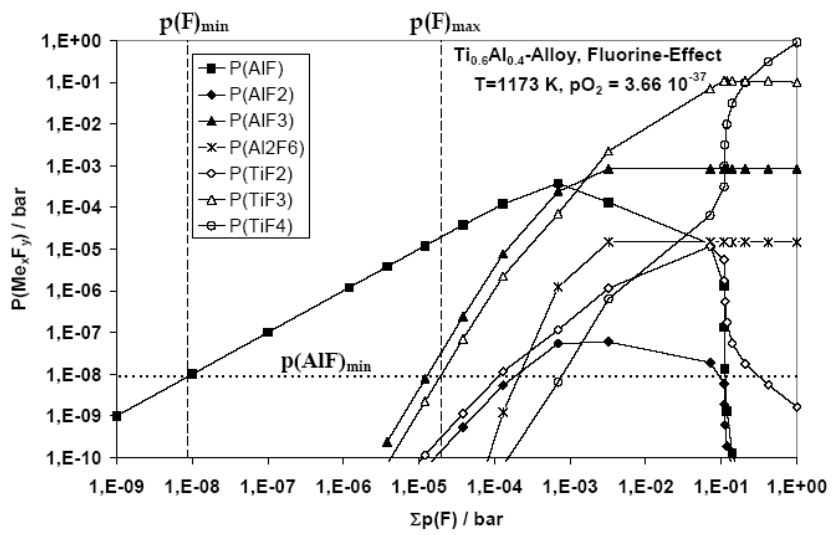

Fig. 4. Partial pressure of several metal fluorides vs. F-total partial pressure for Ti60Al40 at $900^{\circ} \mathrm{C}$ (calculated with FactSage). The region for a positive F-effect is located between the total F-partial pressures of $\mathrm{p}(\mathrm{F})_{\min }$ and $\mathrm{p}(\mathrm{F})_{\max }$. 


\subsection{Determination of the optimal F-concentration for the F-effect in TiAl}

\subsubsection{F-implantation and non-destructive analysis of the implantation profiles}

The corridor for the F-effect found in 3.1 is expressed in terms of fluorine partial pressures. However, for practical applications the fluorine concentration in TiAl is needed. Thus this corridor has to be transformed into a corridor for F-concentrations (in at.\%). However there is no equation between F-pressures and F-concentrations to allow a direct calculation. Therefore a screening has to be performed to study the oxide scale structure after oxidation at $900^{\circ} \mathrm{C}$ with respect to different fluorine amounts within the near-surface region. The beam line ion implantation was chosen because of its accuracy and reproducibility. Based on TRIM-calculations (Ziegler et al., 1995) a F-energy of $20 \mathrm{keV}$ was chosen corresponding to a projected range of about $35 \mathrm{~nm}$ (fig. 5).

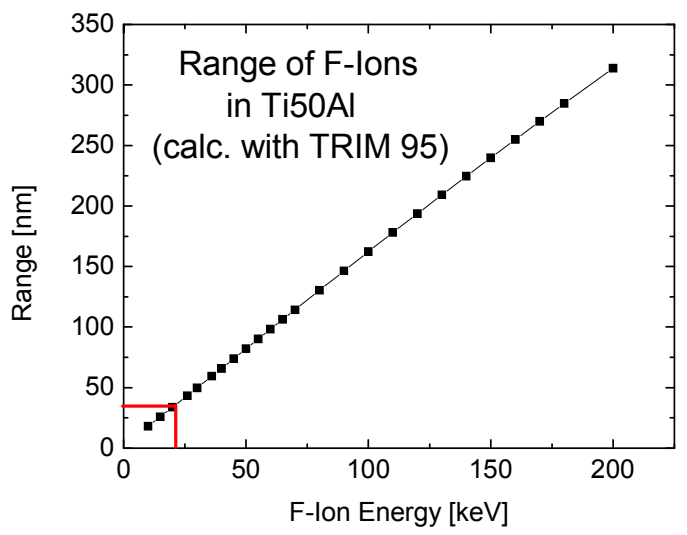

Fig. 5. The projected range for F-ions in TiAl calculated by using TRIM.

The calculation of the F-implantation profiles by using the Monte Carlo-software T-DYN (Biersack, 1999) allows to design the ion implantation prior to the experiment. The calculated

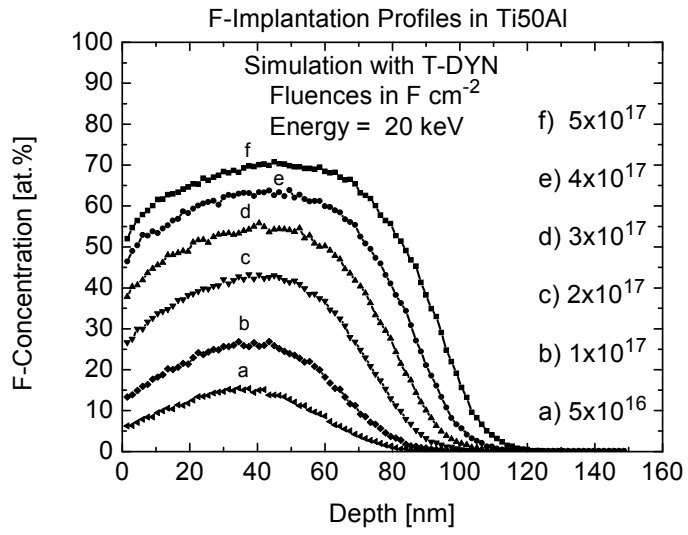

Fig. 6. F-implantation profiles in $\gamma$-TiAl calculated with Monte Carlo simulation software T-DYN. 
F-depth profiles between the fluences of $5 \times 10^{16} \mathrm{~F} \mathrm{~cm}^{-2}$ and $5 \times 10^{17} \mathrm{~F} \mathrm{~cm}^{-2} / 20 \mathrm{keV}$ are illustrated in fig. 6 revealing the corresponding maximal F-concentrations between 15 and 70 at.\%. Due to a sputtering yield of 0.60 the saturation effects occur remarkably above a fluence of $4 \times 10^{17} \mathrm{~F} \mathrm{~cm}^{-2}$. The non-destructive PIGE-technique was used to determine the fluorine concentration depth profiles within the first $1.5 \mu \mathrm{m}$ of the ion implanted samples before and after oxidation. By using the resonance depth profiling the implantation profiles can be verified as depicted in fig. 7. $\mathrm{A} \mathrm{CaF}_{2}-$ single crystal is used as a standard for the quantification of fluorine in at. $\%$.

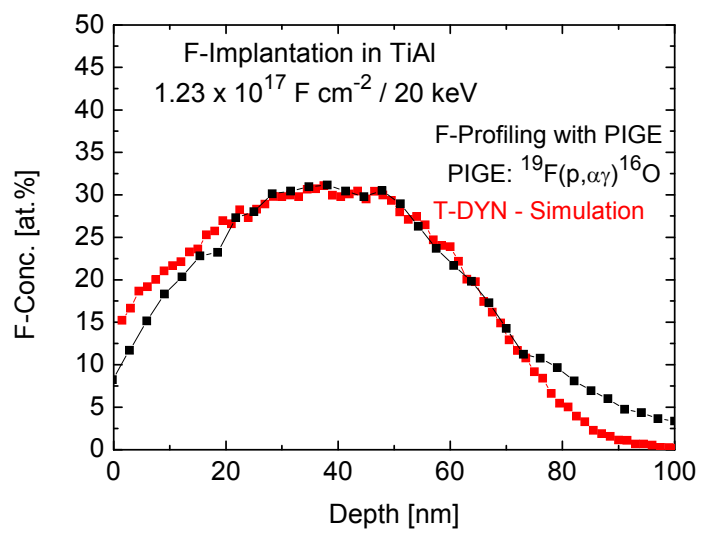

Fig. 7. F-implantation profiles in $\mathrm{\gamma}$-TiAl calculated with Monte Carlo simulation software TDYN and measured by using PIGE.

The F-maximum is shifted into a depth of $35-45 \mathrm{~nm}$ in order to obtain a lower loss of fluorine during the heating process. The small deviations at the surface may be caused by sputtering whereas the differences at the end of the ion range may be influenced by secondary ion collisions.

\subsubsection{Screening of the implantation parameters}

The screening consists of the following steps:

1. Calculation of the F-depth profiles by using Monte Carlo-software T-DYN.

2. F-ion implantation by using the implantation parameters (fluence, ion energy) determined in item 1.

3. Verifying of the F-depth profiles by using PIGE.

4. Oxidation of the implanted samples $\left(24-120 \mathrm{~h} / 900^{\circ} \mathrm{C} /\right.$ air $)$.

5. Measurement of F-depth profiles by using PIGE.

6. Metallographic cross-section preparation.

7. Metallographic inspection of the oxide scale by using SEM/EDX.

8. Definition of the next set of implantation parameters and switch to item 1.

As a criterion for the screening the stability of the F-effect for an oxidation of at least $120 \mathrm{~h} / 900^{\circ} \mathrm{C}$ is required. 

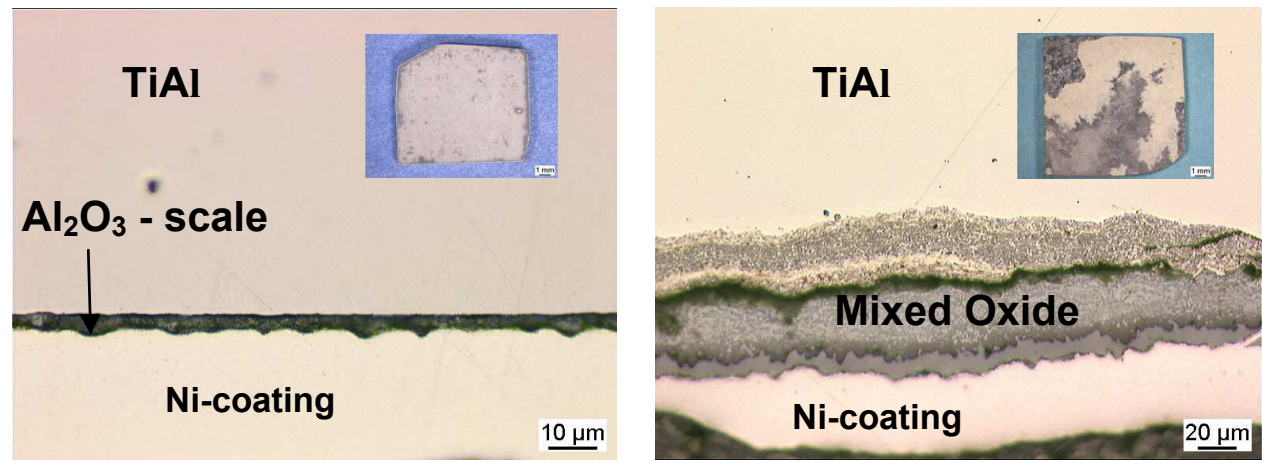

Fig. 8. Cross-section of implanted $\gamma$-TiAl $\left(5 \times 10^{16} \mathrm{~F} \mathrm{~cm}^{-2} / 20 \mathrm{keV}\right)$. The small pictures show the surface. Left image: After oxidation $\left(12 \mathrm{~h} / 900^{\circ} \mathrm{C} /\right.$ air $)$ the surface is covered with a grey thin alumina scale. Right image: After oxidation $\left(120 \mathrm{~h} / 900^{\circ} \mathrm{C} /\right.$ air $)$ the surface is covered with a grey alumina scale, but a mixed oxide scale with a $\mathrm{TiO}_{2}$ - scale on top grows partly on the surface. The Ni-coating is from the metallographic preparation.

A fluence of $10^{16} \mathrm{~F} \mathrm{~cm}^{-2} / 20 \mathrm{keV}$ gives a F-concentration which is too low for the F-effect. Fig. 8 illustrates the initial formation of a thin alumina scale of a TiAl-sample implanted with a fluence of $5 \times 10^{16} \mathrm{~F} \mathrm{~cm}{ }^{-2} / 20 \mathrm{keV}$. After short oxidation $\left(12 \mathrm{~h} / 900^{\circ} \mathrm{C} /\right.$ air $)$ the implanted surface is covered completely with an alumina scale. However after an oxidation time of $120 \mathrm{~h}$ the surface is covered partly by a fast growing mixed oxide scale with $\mathrm{TiO}_{2}$ on top. After implantation of $10^{17} \mathrm{~F} \mathrm{~cm}^{-2} / 20 \mathrm{keV}$ the alumina scale formed remains stable after oxidation of $120 \mathrm{~h} / 900^{\circ} \mathrm{C} /$ air (fig. 9). To obtain a higher F-concentration a fluence of $2 \times 10^{17}$ $\mathrm{F} \mathrm{cm}^{-2} / 20 \mathrm{keV}$ shows the best results even after long term oxidation (fig. 10, 11). The samples implanted with fluences of $3 \times 10^{17} \mathrm{~F} \mathrm{~cm}^{-2} / 20 \mathrm{keV}$ and more show no sufficient alumina scale growth.
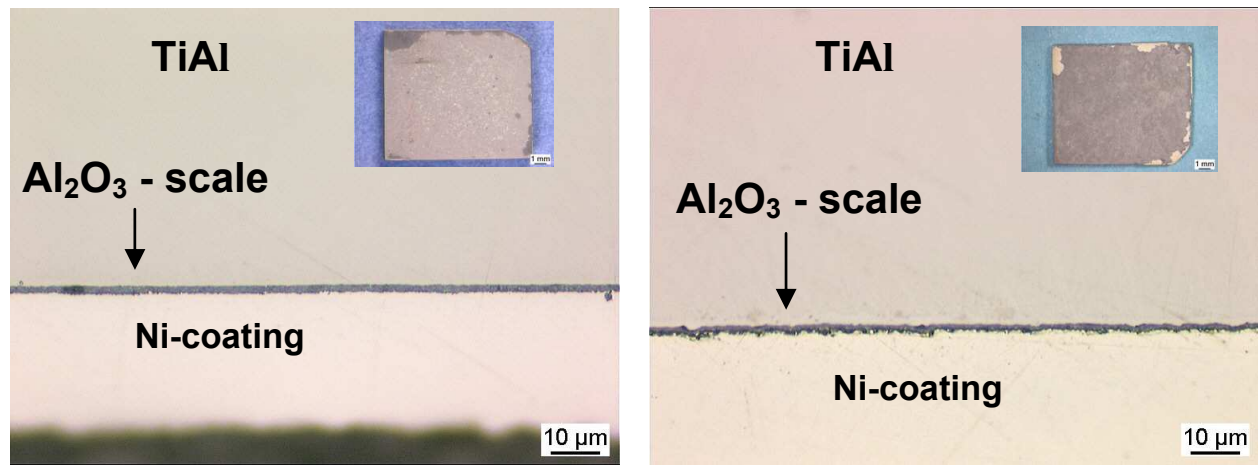

Fig. 9. Cross-section of implanted $\gamma-\mathrm{TiAl}\left(10^{17} \mathrm{~F} \mathrm{~cm}^{-2} / 20 \mathrm{keV}\right)$. The small pictures show the surface. Left image: After oxidation $\left(12 \mathrm{~h} / 900^{\circ} \mathrm{C} /\right.$ air $)$ the surface is covered with a grey thin alumina scale. Right image: After oxidation $\left(120 \mathrm{~h} / 900^{\circ} \mathrm{C} /\right.$ air $)$ the surface is covered with a grey alumina scale, only minor amounts of a mixed oxide scale have been formed the non-implanted edges with a $\mathrm{TiO}_{2}$ - scale on top. 


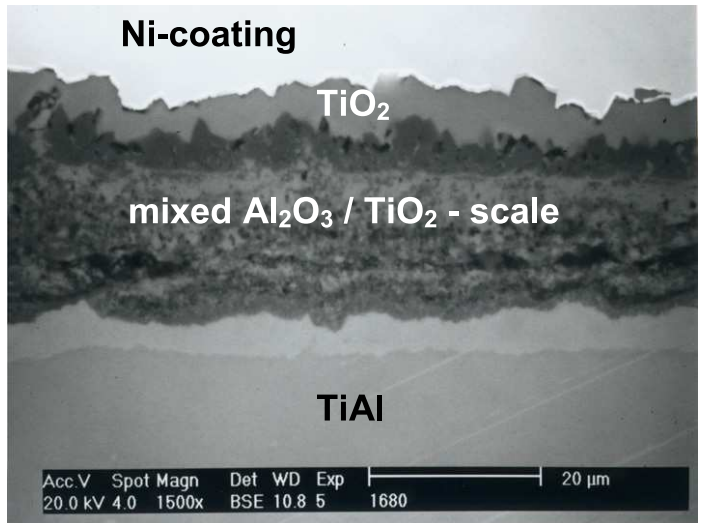

Fig. 10. Non-protective mixed oxide scale on an untreated $\gamma$-TiAl- sample after oxidation $\left(12 \mathrm{~h} / 900^{\circ} \mathrm{C} /\right.$ air $)$.

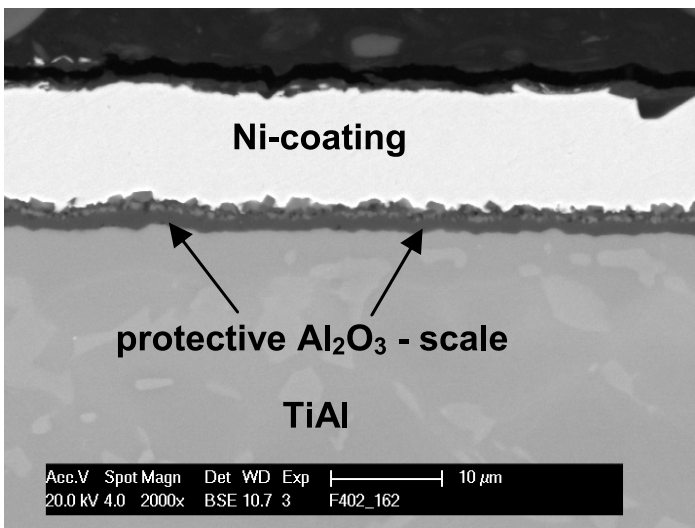

Fig. 11. Protective alumina scale on a F-implanted $\gamma$-TiAl-sample $\left(2 \times 10^{17} \mathrm{~F} \mathrm{~cm}^{-2} / 20 \mathrm{keV}\right)$ after oxidation $\left(1000 \mathrm{~h} / 900^{\circ} \mathrm{C} /\right.$ air $)$.

As a result of the screening an optimal set of implantation parameters $\left(2 \times 10^{17} \mathrm{~F} \mathrm{~cm}^{-2} / 20\right.$ $\mathrm{keV}$ ) has been obtained showing the formation of a pure and dense protective alumina scale on the TiAl-surface (Zschau et al., 2002). This fluence corresponds to a maximal initial Famount of about 44 at.\% as known from the calculation with T-DYN (fig. 6).

\subsection{Behaviour of the implanted fluorine during the oxidation of TiAl}

\subsubsection{Fluorine profile and alumina scale formation}

The non-destructive measurement of the F-depth profiles of implanted and oxidized TiAlsamples by using PIGE reveals a typical shape which can be divided into 3 characteristic regions as shown in fig. 12 (Zschau et al., 2002). Starting with a negligible F-amount on the surface and within the initially formed alumina scale the F-concentration increases to a maximum value $\mathrm{C}_{\mathrm{F}}$ max located at the metal/oxide interface. The position of the 
metal/oxide interface can be verified by RBS-measurements revealing the depth profiles of $\mathrm{O}, \mathrm{Al}$ and $\mathrm{Ti}$ (fig. 13). Within the metal the F-concentration decreases. The shape of the F-profile reveals a distinct F-enrichment in the metal/oxide-interface supporting the suggested mechanism. The alumina scale acts as a diffusion barrier and prevents the Floss via the surface. On the other hand, the fluorine diffuses into the metal. Thus, the behaviour of the F-reservoir at the metal/oxide-interface during long term oxidation determines the stability of the F-effect. Therefore a stable oxidation protection of $\mathrm{TiAl}$ is connected to the presence of a F-reservoir at the interface between the formed $\mathrm{Al}_{2} \mathrm{O}_{3}$-scale and the metal. Additionally the fluorine stimulates the repeated formation of the protective alumina scale once it has been damaged locally.

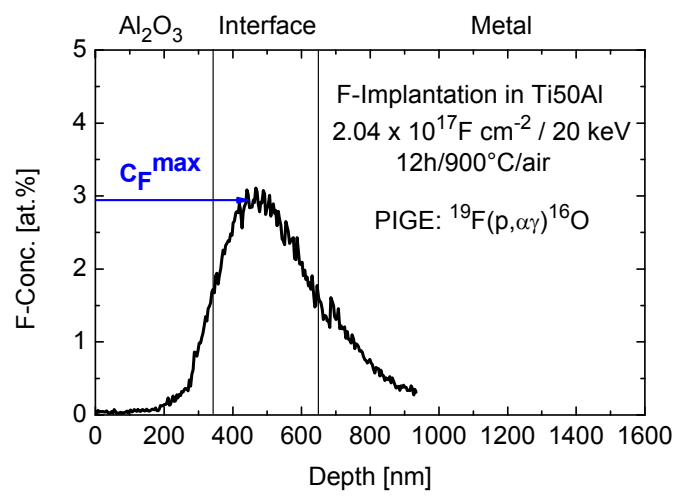

Fig. 12. F-depth profile of a $\gamma$-TiAl sample after oxidation $\left(12 \mathrm{~h} / 900^{\circ} \mathrm{C} /\right.$ air $)$ obtained by PIGE.

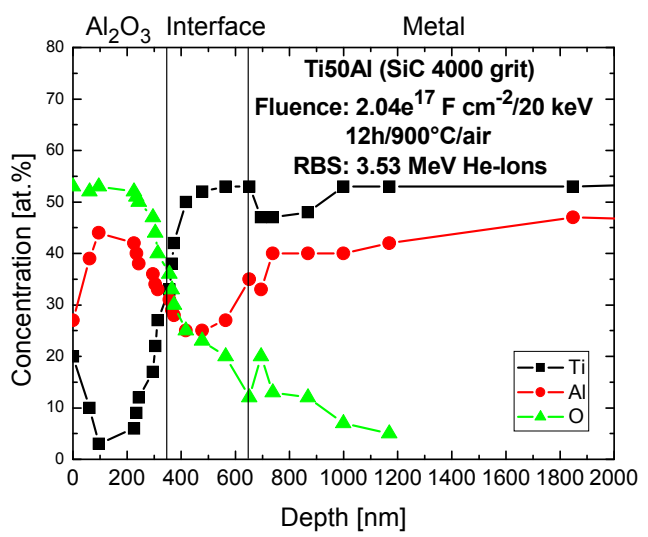

Fig. 13. Depth profiles of $\mathrm{O}, \mathrm{Al}$ and Ti of a $\gamma$-TiAl sample after oxidation $\left(12 \mathrm{~h} / 900^{\circ} \mathrm{C} /\right.$ air $)$ obtained by RBS.

\subsubsection{Dependence of the F-profiles during heating}

The fluorine profiles implanted into TiAl undergo a rapid alteration during the heating process. Starting as a typical implantation profile determined by the fluence and the energy 
of the F-ions, the maximum F-concentration $\mathrm{C}_{\mathrm{F}}$ max decreases rapidly after reaching a temperature of $500^{\circ} \mathrm{C}$. By using a fluence of $2 \times 10^{17} \mathrm{~F} \mathrm{~cm}^{-2} / 20 \mathrm{keV}$ the F-maxima drop to a value of about 5 at. $\%$ after oxidation of $1 \mathrm{~h} /$ air as depicted in fig. 14. The pronounced F-loss is caused by the evaporation of gaseous Ti-fluorides, especially $\mathrm{TiF}_{4}$ (Zschau et al., 2005). For temperatures up to $700^{\circ} \mathrm{C}$ fluorine is present within the near-surface region as a result of the transport to the surface. If the fluorine could escape also at higher temperatures, the Feffect would not be able to work. However at $800^{\circ} \mathrm{C}$ the oxide growth changes from a mixed $\mathrm{Al}_{2} \mathrm{O}_{3} / \mathrm{TiO}_{2}$ - type to pure $\mathrm{Al}_{2} \mathrm{O}_{3}$ as was proven by RBS-measurements. The alumina scale formed inhibits the outward diffusion of fluorine drastically as illustrated by the F-profiles at 900 and $1000^{\circ} \mathrm{C}$ in fig. 14.
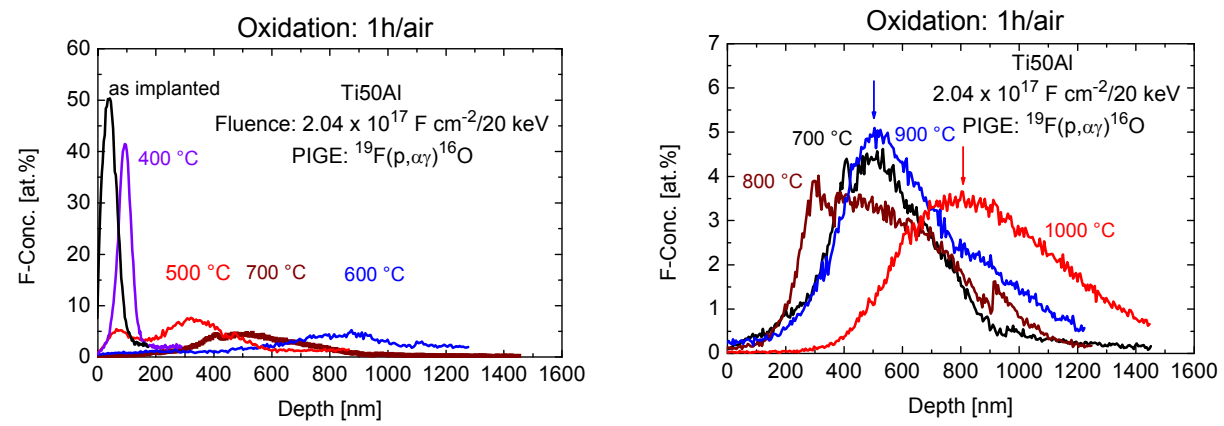

Fig. 14. F-depth profiles of implanted $\gamma$-TiAl- samples $\left(2 \times 10^{17} \mathrm{~F} \mathrm{~cm}^{-2} / 20 \mathrm{keV}\right)$ and after oxidation (1h/air) at temperatures of $400-1000^{\circ} \mathrm{C}$ obtained by PIGE. The arrows denote the position of the metal/oxide-interface.

The development of the fluorine maxima vs. temperature for oxidation (1h/air) is summarized in fig. 15. After the high F-loss between $400-500^{\circ} \mathrm{C}$ the F-maxima decrease slowly reaching values of about 5 at.\%. The integral fluorine concentration (dose) shown in fig. 16 drops to a value between 1.2 and $1.4 \times 10^{17} \mathrm{~F} \mathrm{~cm}^{2}$. A stable oxidation protection is based on the further behaviour of the F-maxima $\mathrm{C}_{\mathrm{F}} \mathrm{max}$. The following sections are focused on the formulation of basic parameters and their influence for the long term stability of the F-effect at TiAl .

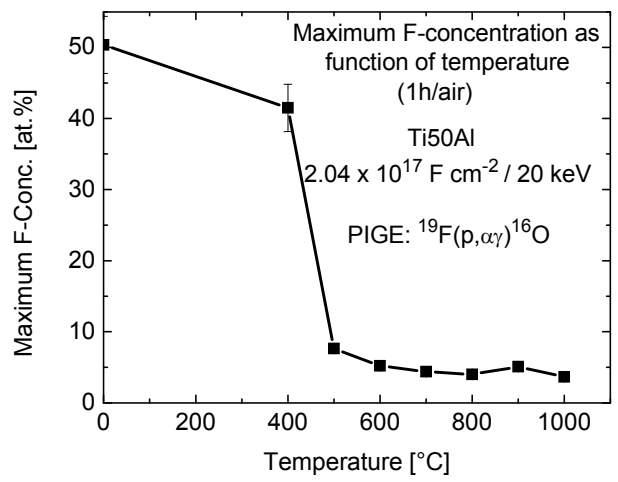

Fig. 15. Behaviour of the F-maxima $\mathrm{C}_{\mathrm{F}} \max$ of implanted $\gamma$-TiAl $\left(2 \times 10^{17} \mathrm{~F} \mathrm{~cm}^{2} / 20 \mathrm{keV}\right)$ during oxidation (1h/air) obtained by PIGE. 


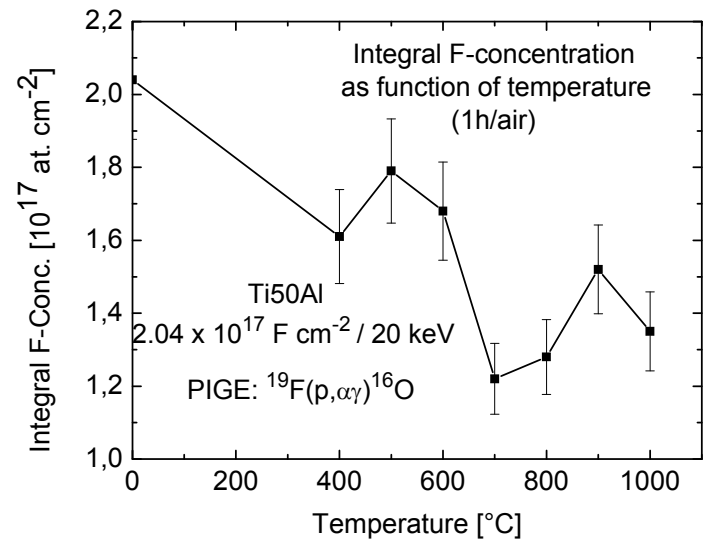

Fig. 16. Behaviour of the F-dose of implanted $\gamma$-TiAl $\left(2 \times 10^{17} \mathrm{~F} \mathrm{~cm}^{2} / 20 \mathrm{keV}\right)$ during oxidation (1h/air) obtained by PIGE.

\subsubsection{Dependence of the F-concentration during long-term oxidation of TiAl}

From a technical point of view the parts manufactured from TiAl have to withstand oxidation for service times of at least 1000 hours under cyclic conditions. Thus the time behaviour of the F-reservoir during long-term oxidation has been investigated by using PIGE after isothermal and cyclic oxidation at $900^{\circ} \mathrm{C}$ and $1000^{\circ} \mathrm{C}$. The time dependence of the F-maximum $\mathrm{C}_{\mathrm{F}} \max$ is chosen to characterize the stability of the F-effect. The formation of a protective alumina scale is confirmed by metallographic preparation and SEM studies. For longer oxidation times the F-maximum drops to $1-2$ at. $\%$ after $500 \mathrm{~h} / 900^{\circ} \mathrm{C}$ (see fig. 17). By considering the F-profiles after isothermal oxidation up to $500 \mathrm{~h} / 900^{\circ} \mathrm{C} /$ air (fig. 17) a nearly stable F-concentration can be expected for oxidation times $>500 \mathrm{~h}$.

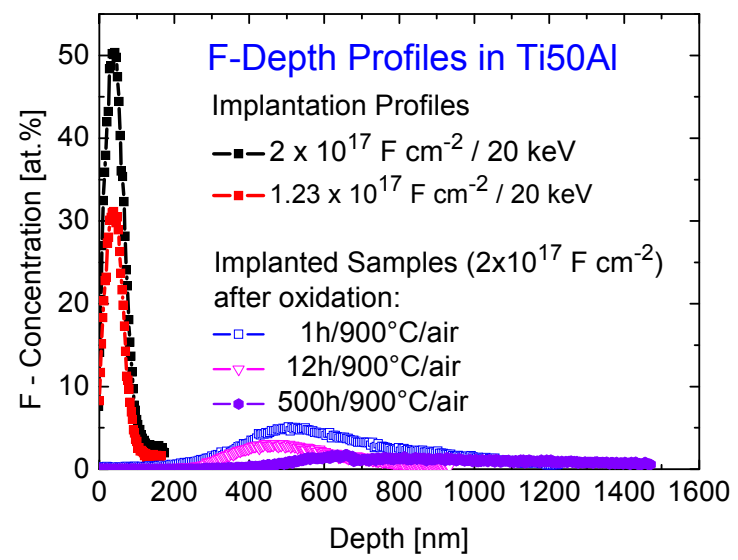

Fig. 17. Time behaviour of the F-depth profiles of implanted TiAl and after isothermal oxidation $\left(900^{\circ} \mathrm{C} /\right.$ air $)$. 


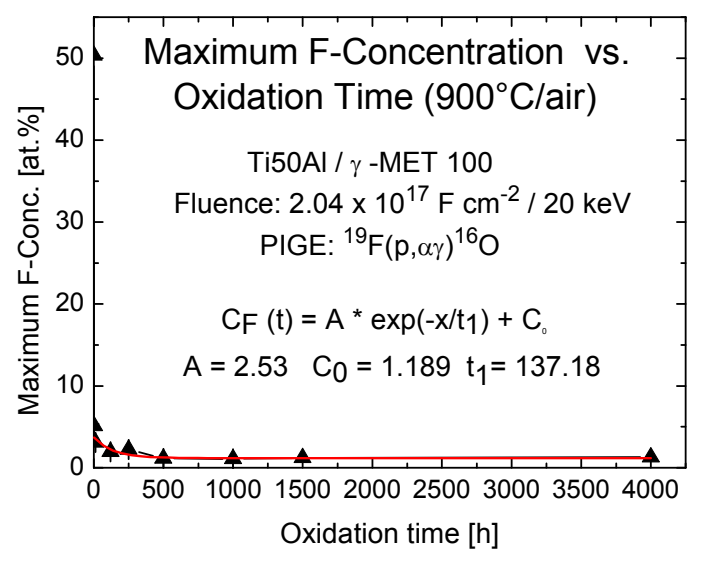

Fig. 18. An exponential decay function (1) with a constant term $\mathrm{c}_{0}$ fits the time behaviour of $\mathrm{C}_{\mathrm{F}} \max \left(2 \times 10^{17} \mathrm{~F} \mathrm{~cm}^{-2} / 20 \mathrm{keV}\right)$ during isothermal oxidation $\left(4000 \mathrm{~h} / 900{ }^{\circ} \mathrm{C} /\right.$ air $)$.

Treatment/Oxidation

\begin{tabular}{lccl}
\hline F-Implant. (900 ${ }^{\circ} \mathrm{C} /$ isoth.) & 2.53 & 1.19 & 137.18 \\
& 6.70 & 3.33 & 13.65 \\
F-Implant. (900 ${ }^{\circ} \mathrm{C} /$ cycl.) & 3.18 & 1.06 & 65.77 \\
& 5.25 & 2.06 & 37.70 \\
F-Implant. (1000 ${ }^{\circ} \mathrm{C} /$ isoth.) & 4.18 & 0.27 & 97.27 \\
& 5.41 & 1.37 & 59.03 \\
F-Implant. (1000 ${ }^{\circ} \mathrm{C} /$ cycl.) & 3.69 & 0.77 & 80.02 \\
& 4.80 & 1.23 & 76.34
\end{tabular}

Table 1. Parameters of the function (1) describing the $\mathrm{C}_{\mathrm{F}} \mathrm{max}$ - dependence after single Fimplantation $\left(2 \times 10^{17} \mathrm{~F} \mathrm{~cm}^{-2} / 20 \mathrm{keV}\right)$ and oxidation of TiAl. The parameters for double implantation are in italics (see section 3.3.4).

In the case of isothermal oxidation at $900^{\circ} \mathrm{C}$ first results have been published in (Zschau \& Schütze, 2008). After extending the oxidation time to $4000 \mathrm{~h}$ (fig. 18) a nearly constant time behaviour of $C_{F} \max$ is obtained as depicted in tab. 1. The SEM inspection confirms a dense protective alumina scale on the sample surface revealing that the F-effect is still working. The time dependence of $\mathrm{C}_{\mathrm{F}}$ max after passing the heating phase can be expressed by an exponential decay function starting at $t=12$ hours of the following type (1), where $t$ denotes the time, $t_{1}$ a time constant, $\mathrm{A}$ the F-amount after the alumina scale has been established and $\mathrm{c}_{0}$ the asymptotic F-concentration:

$$
c_{F}^{\max }(t)=c_{0}+A \exp \left(-\frac{t}{t_{1}}\right)
$$

Equation 1 suggests that after formation of a dense alumina scale $\mathrm{C}_{\mathrm{F}}$ max decreases only slightly approaching a constant value of $\mathrm{c}_{0}$. The fit parameters summarized in tab. 1 allow 
the description of the F-reservoir essential for the oxidation protection reaching a constant value of about 1 at.\%. By increasing the oxidation temperature to $1000{ }^{\circ} \mathrm{C}$ the kinetics of $\mathrm{C}_{\mathrm{F}} \max$ corresponds also to eq. 1 . The parameters in tab. 1 indicate that a fluorine content of 0.27 at. $\%$ stabilizes the $\mathrm{F}$ effect even at $1000{ }^{\circ} \mathrm{C}$ at least within $1000 \mathrm{~h}$. Cyclic oxidation $(1 \mathrm{~h}-$ cycles $/ 900^{\circ} \mathrm{C}$ /air) was performed up to an oxidation time of $2592 \mathrm{~h}$. Before starting the cyclic process a preoxidation was performed to establish a dense alumina scale on the surface. The time behaviour above $12 \mathrm{~h}$ of the F-maximum in fig. 19 has been fitted by eq. 1 , whereas the parameters in tab. 1 reveal the presence of about 1 at. $\%$ fluorine at the metal/oxide interface. The remaining dose shows a constant value of about $7.5 \times 10^{16} \mathrm{~F} \mathrm{~cm}^{-2}$ as can be seen in fig. 20 .

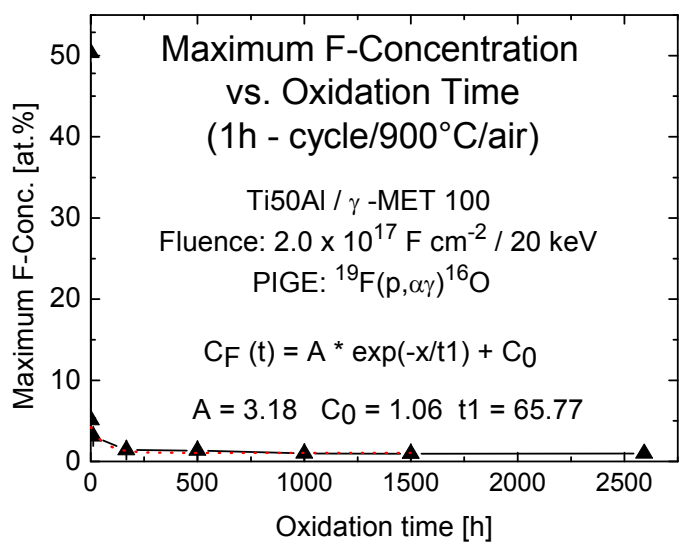

Fig. 19. Exponential decay function with a constant term fits the time behaviour of $C_{F} \max (2 x$ $\left.10^{17} \mathrm{~F} \mathrm{~cm}^{-2} / 20 \mathrm{keV}\right)$ for cyclic oxidation $\left(2592 \mathrm{~h} / 900^{\circ} \mathrm{C} /\right.$ air $)$.

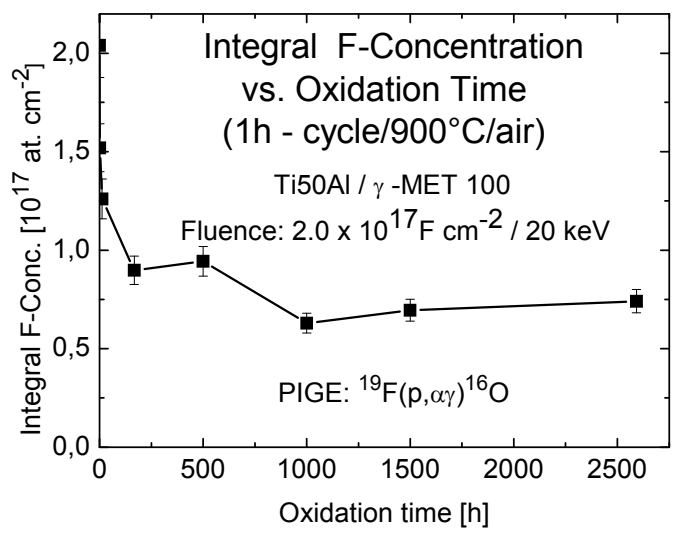

Fig. 20. The fluorine dose remains nearly constant for long oxidation times at TiAl $\left(2 \times 10^{17}\right.$ $\left.\mathrm{F} \mathrm{cm}^{-2} / 20 \mathrm{keV}\right)$ and cyclic oxidation $\left(2592 \mathrm{~h} / 900^{\circ} \mathrm{C} /\right.$ air $)$. 
The results for cyclic loading at $1000 \mathrm{~h} / 1000{ }^{\circ} \mathrm{C}$ indicate the stability of the F-content also under these extreme conditions as summarized in tab. 1 . The F-maximum reaches values of about 0.7 at. $\%$.

In agreement with the metallographic inspections in fig. 21 it was demonstrated that an excellent oxidation protection can be obtained already after single fluorine implantation.

The mass gain obtained by TGA-measurements depicted in fig. 22 shows the existence of an alumina kinetics i. e. a slow growing alumina scale also for cyclic oxidation $(24 \mathrm{~h}-$ cycle $/ 1000 \mathrm{~h} / 900^{\circ} \mathrm{C} /$ air). The excellent oxidation protection of a TiAl-alloy via the F-effect has been demonstrated by the oxidation of a turbocharger rotor with and without fluorine treatment for $1000 \mathrm{~h}$ at $1050^{\circ} \mathrm{C}$ in air (fig. 23). While severely corroded blades are observed for the unprotected rotor, the F-treated rotor is intact and is covered with a protective alumina scale (Donchev et al., 2006).

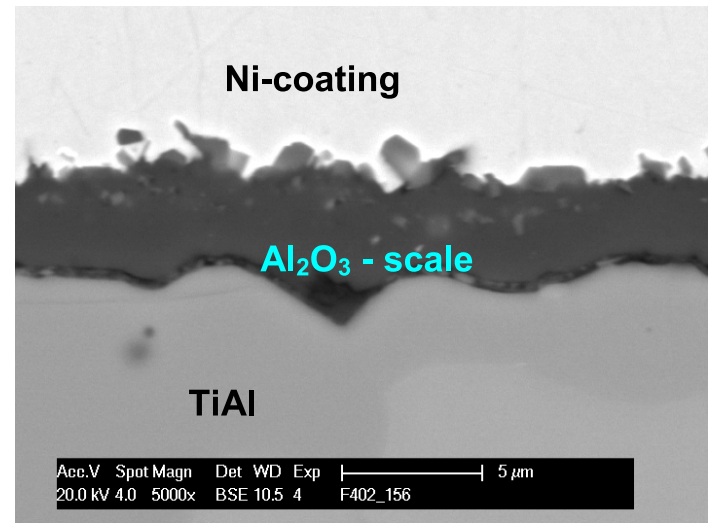

Fig. 21. A $2 \mu \mathrm{m}$ thick protective alumina scale on F-implanted Gamma-Met $\left(2 \times 10^{17} \mathrm{~F} \mathrm{~cm}^{-2}\right.$ $/ 20 \mathrm{keV})$ after oxidation $\left(1000 \mathrm{~h} / 1000^{\circ} \mathrm{C} /\right.$ air $)$.

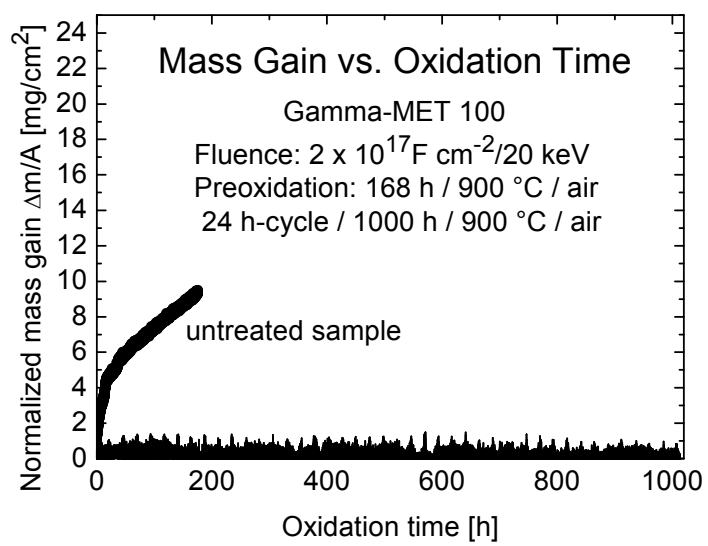

Fig. 22. Mass gain vs. oxidation time of F-implanted Gamma-Met $\left(2 \times 10^{17} \mathrm{~F} \mathrm{~cm}^{-2} / 20 \mathrm{keV}\right)$ during cyclic oxidation $\left(1000 \mathrm{~h} / 900^{\circ} \mathrm{C} /\right.$ air $)$. 

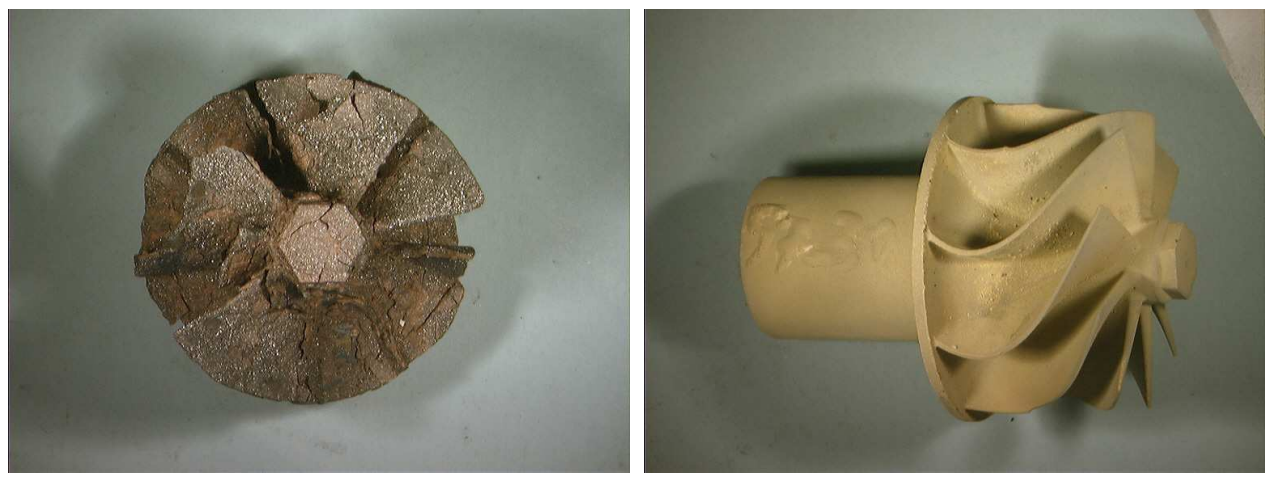

Fig. 23. Turbocharger rotor manufactured from a $\gamma$-TiAl-alloy after oxidation for $1000 \mathrm{~h}$ at $1050^{\circ} \mathrm{C}$ in air. Left image: Untreated rotor. Right image: Fluorine-treated rotor.

\subsubsection{Increase of the F-reservoir by double F-implantation of TiAl}

Despite the good results obtained for single step implanted samples in the present study the formation of an increased F-reservoir should be performed. The basic idea is that the nearsurface implanted $\mathrm{F}$ - after having undergone a high F-loss during heating - has to stimulate the formation of the alumina scale, whereas the deeper implanted fluorine acts as a reservoir for longer oxidation time scales.

To optimize the set of implantation parameters numerous Monte Carlo - simulations were performed by using the software T-DYN. The influence of the implantation parameters in the case of double implantation is illustrated in fig. 24. From the results two implantation strategies have been suggested. The first implantation is done with the higher energy (55 $\mathrm{keV})$ followed by the second implantation with a lower energy $(20 \mathrm{keV})$. In these cases the implantation profiles show a near-surface peak with a maximum located in a depth of 30-40 $\mathrm{nm}$, followed by a lower second peak in a depth of about $100-140 \mathrm{~nm}$. The second strategy

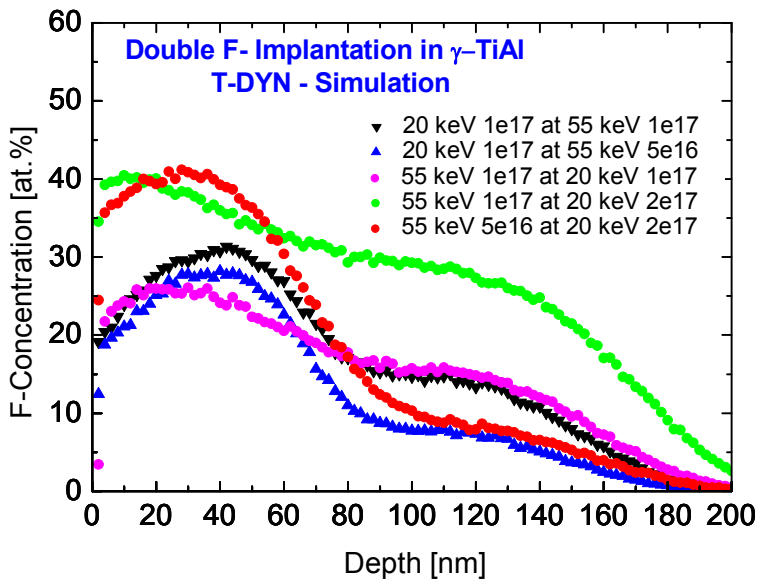

Fig. 24. F-depth profiles for double implantation into TiAl calculated by using T-DYN. 
works in the reverse way: The high energy implantation is followed after a low energy implantation. These profiles show a more flat behaviour, so that the difference between the two maxima decreases. This can be explained by the implantation process: During the high energy implantation a part of the ions collides with the near-surface fluorine from the former implantation step leading to a smoother depth profile.

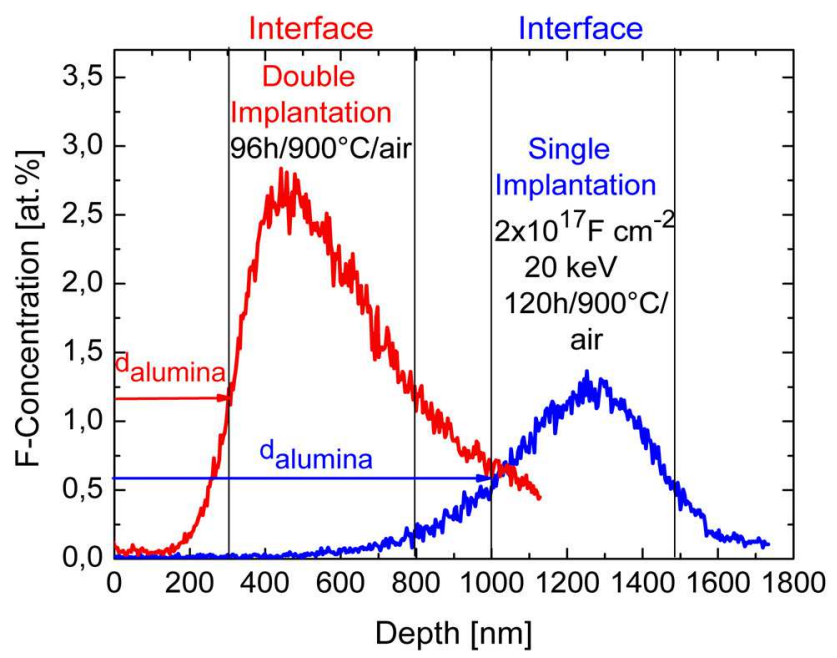

Fig. 25. F-depth profiles after oxidation of single implanted $\left(120 \mathrm{~h} / 900^{\circ} \mathrm{C}\right)$ and double implanted $\left(96 \mathrm{~h} / 900^{\circ} \mathrm{C}\right)$ TiAl-samples (see text).

In principle, by using more implantation steps a nearly rectangular implantation profile can be obtained. To choose a suitable set of implantation parameters one has to take into account that the near-surface implanted $\mathrm{F}$ is reduced during heating. In contrast to this the deeper implanted fluorine should be less affected by the fluorine loss. Therefore the F-reservoir requires a lower F-maximum compared to the near-surface level. Keeping this in mind the first strategy was chosen with $10^{17} \mathrm{~F} \mathrm{~cm}^{-2} / 55 \mathrm{keV}$ as first and $10^{17} \mathrm{~F} \mathrm{~cm}^{-2} / 20 \mathrm{keV}$ as the second step. The difference between single and double implantation is illustrated by the obtained F-depth profiles in fig. 25 after comparable oxidation times. Both F-maxima are located at the metal/oxide interface. While in the single-step case the F-maximum is in a depth of about $1250 \mathrm{~nm}$, for the two-step sample the F-maximum occurs distinctly closer to the surface. The underlying area - this corresponds to the remaining F-dose - after double implantation is twice as high as that of the single implantation case. The near-surface region without fluorine corresponds to the alumina scale. Once formed the alumina scale acts as a diffusion barrier for fluorine and prevents further F-loss from the surface. From fig. 25 it can be concluded that the alumina growth after two-step implantation is slower compared to the single-step case. This is in agreement with the micrograph showing the cross-section in fig. 26. The alumina scale is characterized by a thickness of $<1 \mu \mathrm{m}$ in most cases. In the buckling structures F-enriched regions are visible which serve as main F-reservoirs. Because of the $1 \mathrm{~mm}$ diameter of the proton beam spot of PIGE the F-depth profiles in fig. 25 represent an area averaged information. The time development of $\mathrm{C}_{\mathrm{F}}$ max for isothermal and cyclic oxidation at $900^{\circ} \mathrm{C} / 1000 \mathrm{~h}$ reveals a significantly increased F-reservoir at the 
metal/oxide interface. The fit-parameters according to equ. (1) for double implantation are summarized in tab. 1.

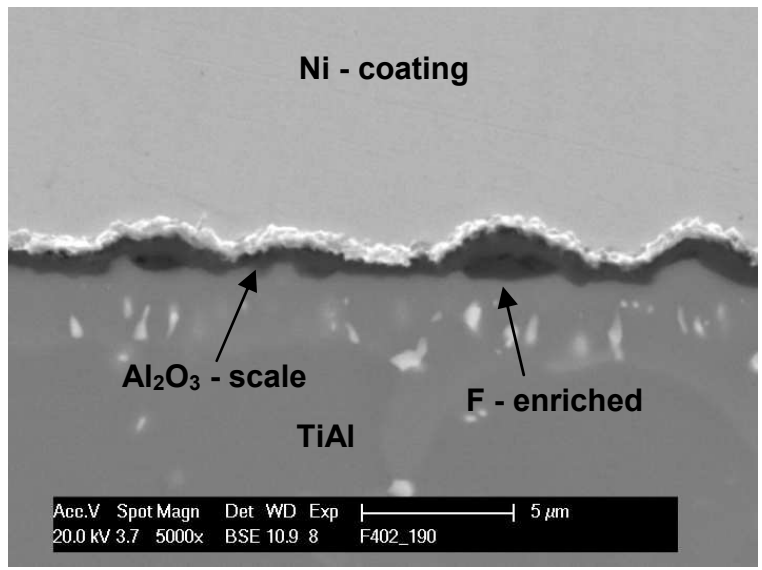

Fig. 26. Alumina scale with F-reservoirs on the surface of a Gamma-Met 100-sample after Fdouble implantation as described in the text and oxidation $\left(1000 \mathrm{~h} / 900^{\circ} \mathrm{C} /\right.$ air $/$ isothermal $)$.

\subsubsection{Diffusion coefficient of fluorine in TiAl}

After the growth of the alumina scale has been started, the remaining fluorine must be localized within the metal/oxide interface to act as a reservoir for slow alumina growth during long term oxidation protection of TiAl. Once formed, the alumina scale acts as a diffusion barrier for the remaining $\mathrm{F}$ into the alloy preventing a further F-loss to the surface. On the other hand, the time behaviour of the F-profiles during oxidation at $900^{\circ} \mathrm{C}$, depicted in fig. 27, suggests a slow diffusion process into the metal. A basic parameter for the stability of this F-reservoir is the diffusion coefficient of $\mathrm{F}$ in $\mathrm{TiAl}$ at $900^{\circ} \mathrm{C}$. There were no data available up to now. Based on the F-depth profiles after oxidation of 12, 120, 250 and 500h at $900^{\circ} \mathrm{C}$ illustrated in fig. 27 a first determination has been performed (Zschau et al., 2007; Zschau \& Schütze, 2008) by using the diffusion equation

$$
\frac{\partial c}{\partial t}=D \frac{\partial^{2} c}{\partial x^{2}}
$$

where $\mathrm{c}$ is the fluorine concentration in at. $/ \mathrm{cm}^{3}, \mathrm{t}$ is the oxidation time, $\mathrm{x}$ the distance from the metal/oxide interface into the metal and $\mathrm{D}$ the diffusion coefficient in $\mathrm{cm}^{2} / \mathrm{s}$. The analytical solution is given by the formula (3) (Philibert, 1990)

$$
c(x, t)=\frac{Q}{2 \sqrt{D t \pi}} \exp \left(-\frac{x^{2}}{4 D t}\right)
$$

with $\mathrm{Q}$ denoting the number of fluorine atoms in at./ $\mathrm{cm}^{2}$ remaining at the metal/oxide interface after oxidation of $12 \mathrm{~h} / 900^{\circ} \mathrm{C}$. By getting the logarithmic form of equation (3) the diffusion coefficient $\mathrm{D}$ can be calculated as follows 


$$
\ln c=\ln \left(\frac{Q}{2 \sqrt{D t \pi}}\right)-\frac{x^{2}}{4 D t}
$$

which is a linear function with respect to $x^{2}$. By supposing that after 2 hours of oxidation the initial alumina scale has been formed and hinders the F-loss outwards, the diffusion of $F$ into the metal is the dominating process. After the transformation of the depth profiles the fit of the parameter D leads to the results summarized in tab. 2 .

\section{Oxidation time Diffusion Coefficient $\left[10^{-15} \mathrm{~cm}^{2} / \mathrm{s}\right]$}

$120 \mathrm{~h}$

$250 \mathrm{~h}$

$500 \mathrm{~h}$

$2.55+-0.84$

$0.72+-0.18$

$$
1.41+-0.51
$$

Table 2. Diffusion coefficients of fluorine in $\mathrm{TiAl}$ at $900^{\circ} \mathrm{C}$ calculated from the fluorine depth profiles of the implanted TiAl-samples. The mean value is $\mathrm{D}=1.56 \times 10^{-15} \mathrm{~cm}^{2} \mathrm{~s}^{-1}$.

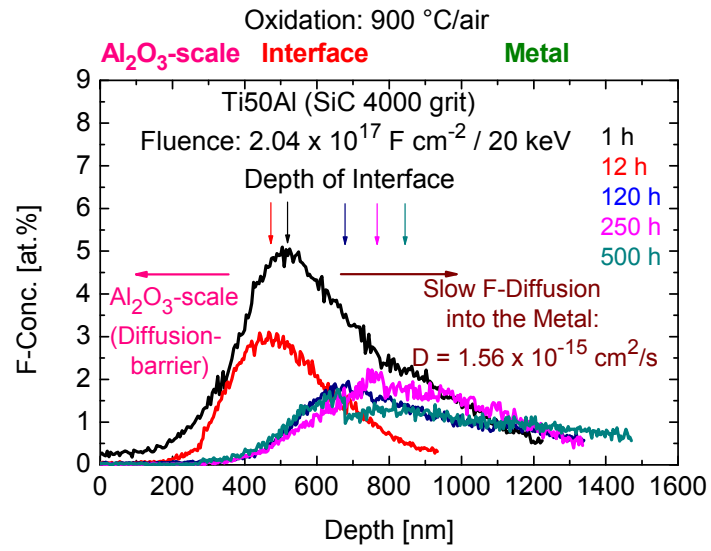

Fig. 27. Time behaviour of the F-depth profiles of implanted $\left(2 \times 10^{17} \mathrm{~F} \mathrm{~cm}^{-2} / 20 \mathrm{keV}\right) \mathrm{TiAl}$ after isothermal oxidation $\left(1,12,120,250\right.$ and $500 \mathrm{~h}$ at $900{ }^{\circ} \mathrm{C}$ in air).

The F-profiles have been determined by using PIGE without removing the $\mathrm{Al}_{2} \mathrm{O}_{3}-$ scale, which may explain the scatter within one order of magnitude of the diffusion coefficient. The influence of the chemical bonding of fluorine cannot be taken into account, because the PIGE-technique is sensitive only to the nucleus ${ }^{19} \mathrm{~F}$ - independently of its chemical environment. Additionally an irregular behaviour of the metal/oxide interface may influence the scatter. The stability of the F-effect is determined by the main parameters as illustrated in fig. 27: The $\mathrm{Al}_{2} \mathrm{O}_{3}$ - scale as a diffusion barrier inhibits the F-loss to the surface, whereas the low diffusion coefficient of $\mathrm{F}$ in TiAl of $\mathrm{D}=1.56 \times 10^{-15} \mathrm{~cm}^{2} \mathrm{~s}^{-1}$ limits the Fdiffusion into the metal. The knowledge of the diffusion coefficient allows the calculation of the F-maximum $\mathrm{C}_{\mathrm{F}} \mathrm{mac}$ vs. oxidation time at $900^{\circ} \mathrm{C}$ (fig. 28). By setting $\mathrm{Q}=1.26 \times 10^{17} \mathrm{~F}$-at. $\mathrm{cm}^{-2}$ as the number of F-atoms at the metal/oxide interface after $12 \mathrm{~h}$ of isothermal oxidation (fig. 29) $\mathrm{C}_{\mathrm{F}}$ mac shows a similar behaviour compared to the experimental values. 


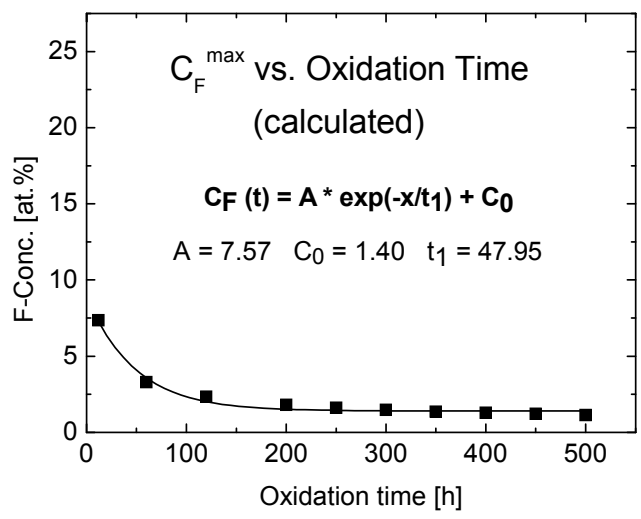

Fig. 28. Modelling of the F-maximum $\mathrm{C}_{\mathrm{F}} \max$ at the metal/oxide-interface during oxidation at $900^{\circ} \mathrm{C}$.

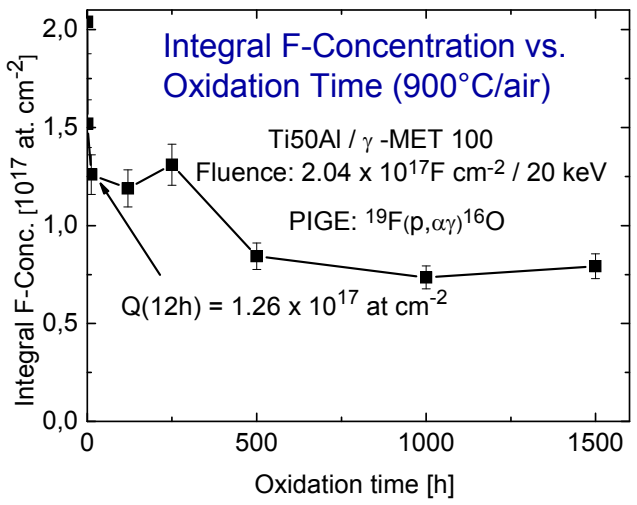

Fig. 29. Behaviour of the F-dose of implanted $\gamma$-TiAl $\left(2 \times 10^{17} \mathrm{~F} \mathrm{~cm}^{2} / 20 \mathrm{keV}\right)$ during isothermal oxidation $\left(1500 \mathrm{~h} / 900^{\circ} \mathrm{C} /\right.$ air $)$ obtained by PIGE.

\subsection{Surface modification of $\mathrm{Ni}$-base superalloys by fluorine ion implantation}

\subsubsection{Principles of the halogen effect for $\mathrm{Ni}$-base superalloys}

Most technical Ni-base alloys are so-called borderline materials from an oxidation point of view, i. e. their Al-contents of $2-5$ wt.\% are not sufficient to form a continuous dense and protective aluminium oxide layer on the surface. Unprotected Ni-base borderline alloys form a fast growing mixed oxide scale consisting of oxides and spinels from $\mathrm{Ni}, \mathrm{Cr}, \mathrm{Al}$ and other alloying elements with high metal consumption rates and limited barrier effect against ingress of species from the operating environment. Underneath the fast growing oxide scale internal oxidation takes place leading to discrete aluminium oxide particles which do not form a continuous diffusion barrier (Litz et al., 1989; Nickel et al., 1999; Pint et al., 2006). Additionally nitrides are formed at the metal/oxide interface due to the inward diffusing nitrogen. As one possibility to protect these alloys against oxidation at temperatures above 
$1000^{\circ} \mathrm{C}$ Al-rich coatings were applied. Today this method has become a state-of-the-art process for the manufacturing of components for high temperature technology like turbine blades for gas fired power stations and aircraft engines. Typical borderline alloys are IN738 and IN939 whose compositions are given in tab. 3.

\begin{tabular}{|ccccccccccc|} 
Alloy & $\mathrm{Ni}$ & $\mathrm{Co}$ & $\mathrm{Cr}$ & $\mathrm{Al}$ & $\mathrm{W}$ & $\mathrm{Mo}$ & $\mathrm{C}$ & $\mathrm{Ti}$ & $\mathrm{Ta}$ & Others \\
\hline IN738 & 61.13 & 9.0 & 16.00 & 3.30 & 1.70 & 2.60 & 0,17 & 3.50 & 1.70 & $0.90 \mathrm{Nb}$ \\
IN939 & 48.35 & 20 & 22 & 1.4 & 2 & & 0.15 & 3.8 & 1.3 & $1.0 \mathrm{Nb}$
\end{tabular}

Table 3. Composition of the Ni-base alloys IN738 und IN939 (in wt.\%).

Wagner`s oxidation theory (Kofstad, 1988) predicts the formation of a dense alumina scale, if the Al-activity is sufficiently high. Based on this a detailed calculation of the minimum (or critical) Al-concentration $\mathrm{N}_{\mathrm{c}}$ for several Ni-base alloys has been performed (Zschau et al., 2009a). Three groups of alloys were considered according to their Al-content: Chromia formers (group 1), alumina formers (group 2) and bond coats (group 3). The results summarized in fig. 30 reveal a strong dependence of $N_{c}$ on temperature, but only a weak dependence on the chemical composition of the alloy. By considerung the alloys of group 1 the formation of a protective external $\mathrm{Al}_{2} \mathrm{O}_{3}$ - scale is possible above the borderline (i. e. the calculated $\mathrm{N}_{\mathrm{c}}$ - curve), whereas beneath the borderline internal oxidation of $\mathrm{Al}$ takes place. The basic idea is to shift the borderline between alumina and chromia formers to lower Alconcentrations which allows the formation of a dense alumina scale at lower Al-contents of the bulk alloys. This can be achieved by increasing the outward mobility of $\mathrm{Al}$ on the surface by using the halogen effect. The halogen effect was applied already succesfully for TiAl-alloys as shown in the previous sections.

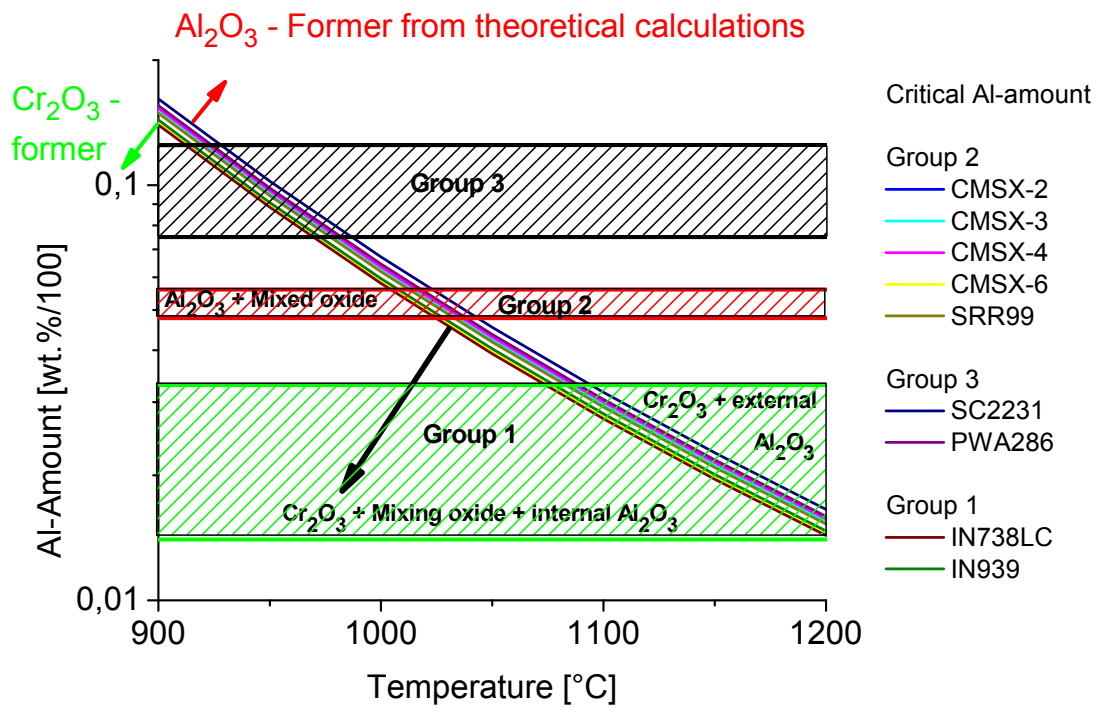

Fig. 30. Calculated minimal Al-concentration $\mathrm{N}_{\mathrm{c}}$ required for the formation of a continuous alumina scale (external oxidation) for several Ni-based alloys (Zschau et al., 2009a). 
Following the thermodynamic considerations for TiAl the ability of the selective formation of Al-fluorides as the basic condition has to be studied. The fig. 31 shows possible reactions at the metal/oxide interface. Thermodynamical calculations were carried out for the alloys IN738 and IN939 by using the software FactSage. All calculations assume thermodynamic equilibrium and an infinite system. Because no data bases for Nibase alloys and fluorine or chlorine were available up to now, new data bases had to be developed. The calculations were performed for $\mathrm{F}$ and $\mathrm{Cl}$ and both alloys at temperatures between $900-1200^{\circ} \mathrm{C}$. The results for Fluorine and IN738 at $1000^{\circ} \mathrm{C}$ are summarized in fig. 32, where the minimum $\mathrm{F}$ partial pressure $\mathrm{p}(\mathrm{AlF})_{\min }$ for a significant formation of $\mathrm{AlF}$ is denoted. By increasing the total F-partial pressure to $\mathrm{p}(\mathrm{F})_{\min }$ the partial pressure of gaseous AlF meets the value of $\mathrm{p}(\mathrm{AlF})_{\min }$ which opens the window for the F-effect. The effect works until the partial pressures of gaseous fluorides of other alloying elements $(\mathrm{Ni}$, $\mathrm{Cr}, \mathrm{Co}, \mathrm{Ti} . .$.$) reach the value of the minimal partial pressure \mathrm{p}(\mathrm{AlF})_{\min }$ too defining the partial pressure $\mathrm{p}(\mathrm{F})_{\max }$ and leading to the formation of a mixed oxide scale. Hence a positive F-effect is possible within the corridor between $\mathrm{p}(\mathrm{F})_{\min }$ and $\mathrm{p}(\mathrm{F})_{\max }$. The results of the calculations are summarized in fig. 33 showing the behaviour of this corridor within the temperature range of $900-1200^{\circ} \mathrm{C}$. From fig. 33 it can be concluded, that the F-effect is possible for IN738 within this temperature range $900-1200^{\circ} \mathrm{C}$. The calculation for IN939 shows similar results. For $\mathrm{Cl}$ a positive effect is predicted too (Zschau et al., 2009b). However due to the good results obtained for $\mathrm{F}$ at TiAl the investigations have been continued with fluorine.

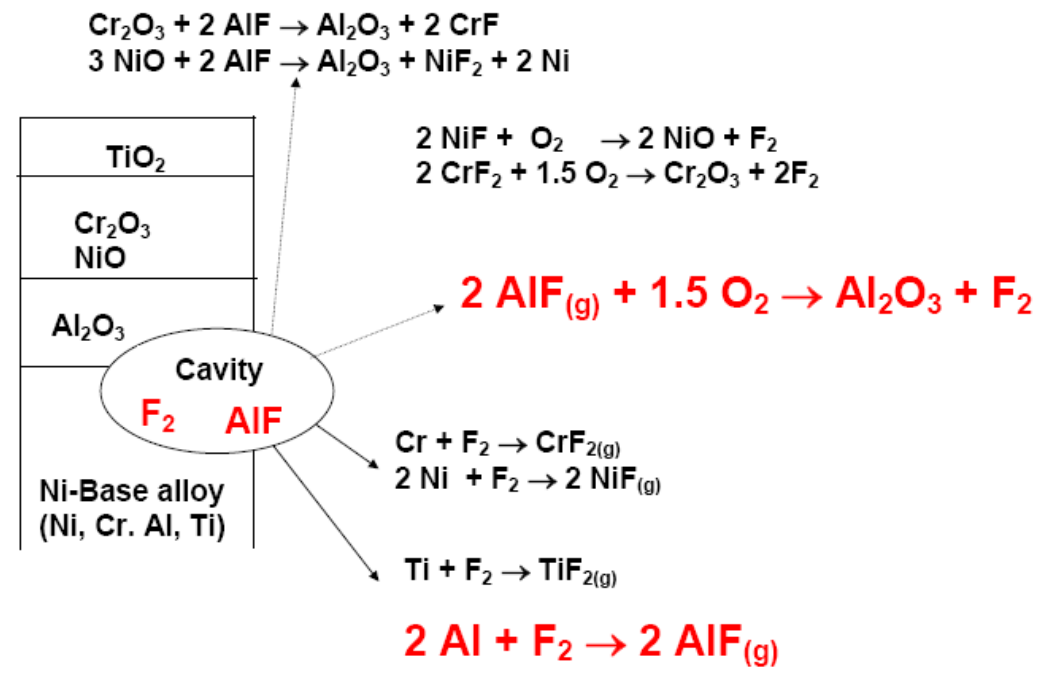

Fig. 31. Selected possible reactions in the F-doped subsurface zone of the Ni-base alloy IN738 during the initial oxidation stage. 


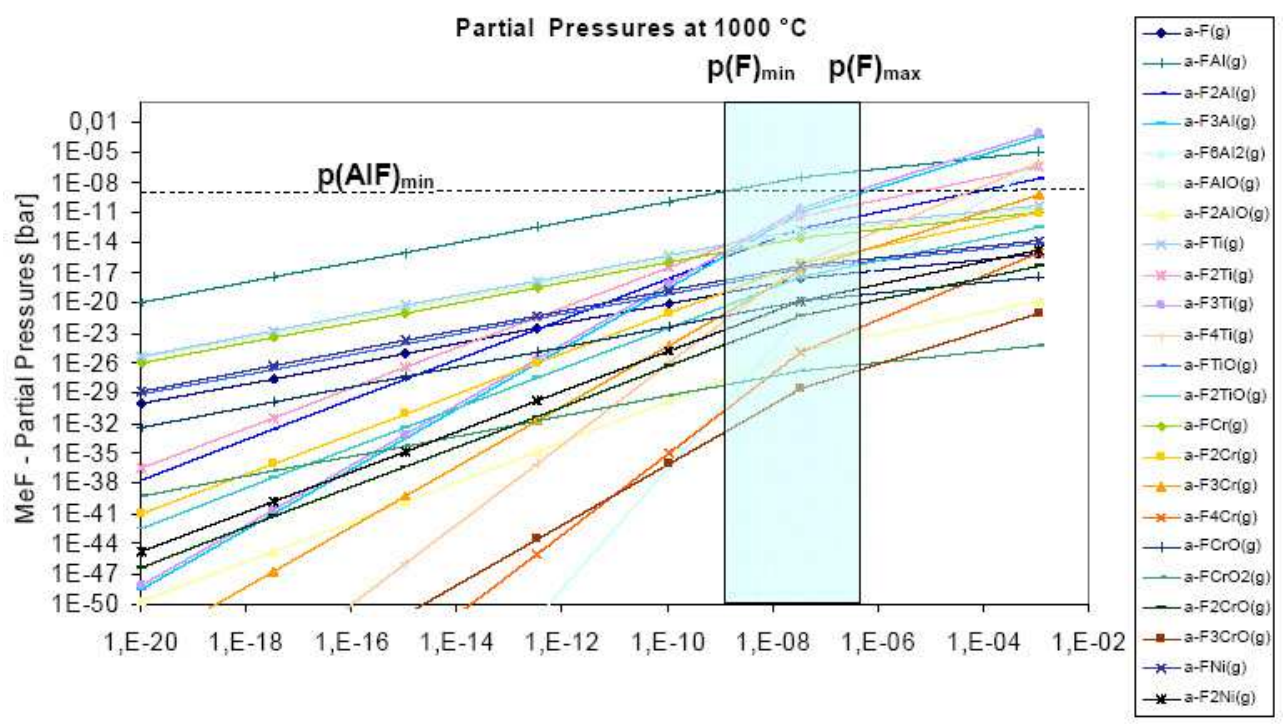

F-Total Partial Pressure [bar]

Fig. 32. Partial pressures of several metal fluorides vs. total F-partial pressure at $1000^{\circ} \mathrm{C}$ for the Ni-base alloy IN738 (calculated with FactSage).

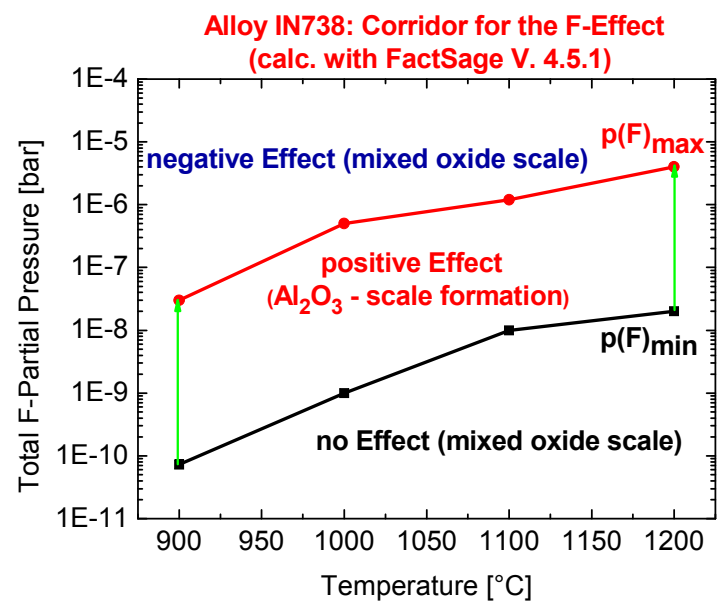

Fig. 33. Corridor of a positive fluorine effect for the alloy IN738 between $900^{\circ} \mathrm{C}$ and $1200^{\circ} \mathrm{C}$ (calculated with FactSage).

\subsubsection{Screening of the implantation parameters for Ni-base superalloys}

As already discussed for TiAl the calculated optimal fluorine partial pressures for the positive fluorine effect cannot be transformed into fluorine concentrations by straightforward calculations. Therefore a screening of the fluorine amount near the surface 
is necessary by using beam line ion implantation. The implantation profiles for fluences between $10^{16}$ and $4 \times 10^{17} \mathrm{~F} \mathrm{~cm}^{-2} / 38 \mathrm{keV}$ calculated by using the Monte Carlo software TDYN are shown fig. 34. The energy of $38 \mathrm{keV}$ meets the projected range of about $35 \mathrm{~nm}$ as was selected in the TiAl-case. The calculated F-profiles cover the range of fluorine amounts between 2 and 44 at\%. For fluences above $4 \times 10^{17} \mathrm{~F} \mathrm{~cm}^{-2}$ a saturation effect was found, hence higher fluences were not considered. Following these results implantations were carried out on one side of the samples with fluences between $10^{16}$ and $4 \times 10^{17} \mathrm{~F} \mathrm{~cm}^{-2}$ at a constant ion energy of $38 \mathrm{keV}$. The F-profiles obtained with PIGE (Zschau et al., 2009c) reveal the good agreement between calculated and implanted F-depth profiles (fig. 35). The minor deviations at the end of the ion range may be caused by secondary ion collisions and the sputter process can explain the small differences near the surface.

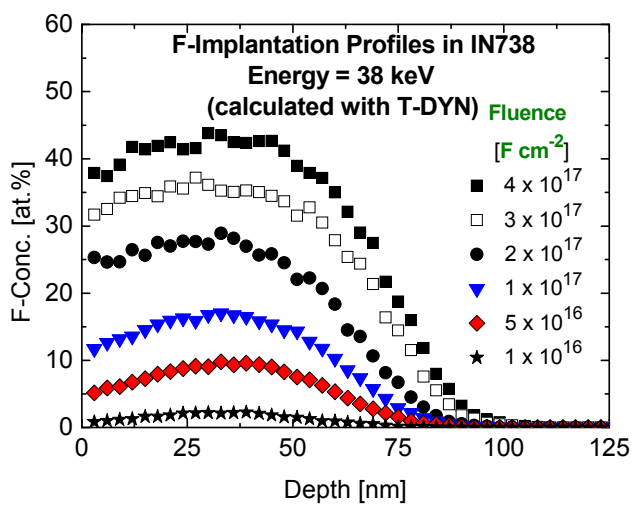

Fig. 34. F-implantation profiles in the alloy IN738 calculated by using the Monte Carlo program T-DYN.

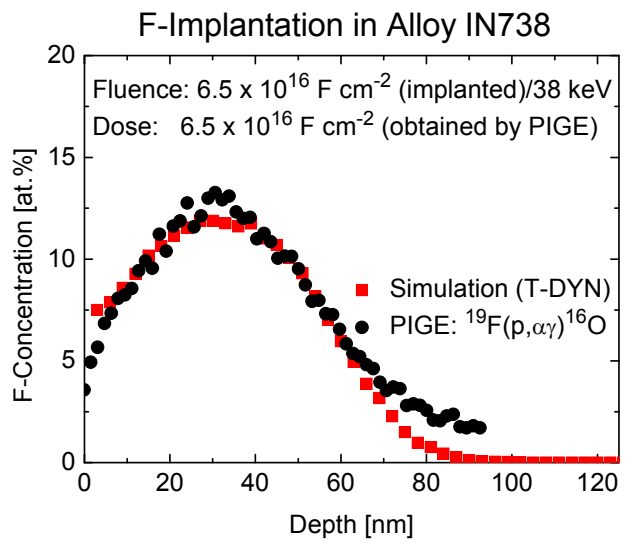

Fig. 35. Comparison of the implanted (obtained by using PIGE) and calculated F-depth profile (T-DYN) in the Ni-base alloy IN738.

After oxidation at $1050^{\circ} \mathrm{C}$ /air between $24 \mathrm{~h}$ and $168 \mathrm{~h}$ and metallographic preparation the SEM-micrographs reveal a change of the oxidation mechanism. The non-implanted side 
$\left(24 \mathrm{~h} / 1050^{\circ} \mathrm{C} /\right.$ air $)$ shows an outer porous $\mathrm{Cr}_{2} \mathrm{O}_{3}$ - scale and an inwards growing $\mathrm{Al}_{2} \mathrm{O}_{3}-$ scale (fig. 36a). The porous chromia rich layer as well as the inward growing rather discontinuous alumina scale do not protect the metal against the inward diffusion of oxygen and nitrogen. Hence also needle-like Ti-nitrides are observed up to a depth of 30-40 $\mu \mathrm{m}$ within the metal. In contrast to this the implanted side $\left(1 \times 10^{17} \mathrm{~F} \mathrm{~cm}^{-2} / 38 \mathrm{keV}\right)$ after oxidation of $60 \mathrm{~h} / 1050^{\circ} \mathrm{C} /$ air reveals a completely different behaviour (fig. 36b): An outer $\mathrm{Ni}$-Al-spinel scale covers a continuous alumina scale of $1-2 \mu \mathrm{m}$ thickness. No internal nitrides were found. Minor inclusions of alumina are visible showing the tendency for a change from internal to external oxidation.

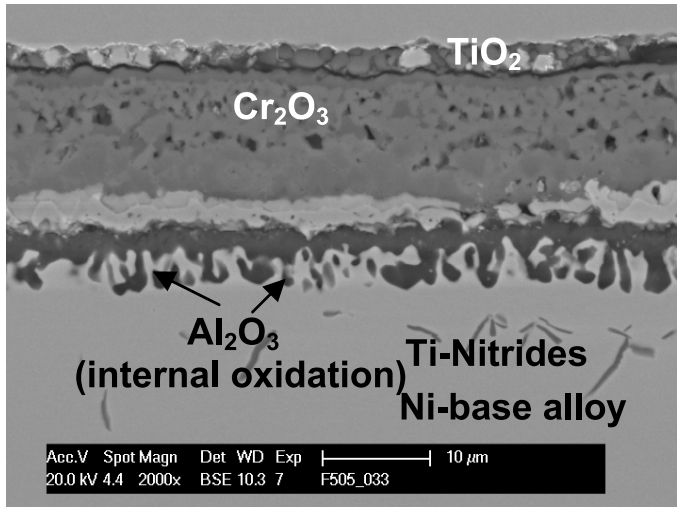

Fig. 36. a) The cross-section of the untreated Ni-base alloy IN738 after oxidation $\left(24 \mathrm{~h} / 1050^{\circ} \mathrm{C} /\right.$ air $)$ shows a non-protective internal alumina scale.

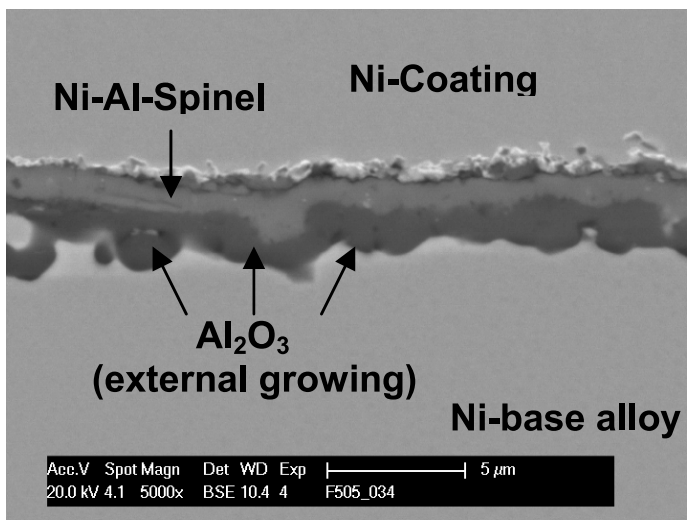

Fig. 36. b) The cross-section of the F-implanted (1017 $\left.\mathrm{F} \mathrm{cm}^{-2} / 38 \mathrm{keV}\right)$ Ni-base alloy IN738 after oxidation $\left(60 \mathrm{~h} / 1050^{\circ} \mathrm{C} /\right.$ air $)$ reveals a protective alumina scale.

As a result of the screening the F-effect was found to be working between $5 \times 10^{16}$ and $4 \times$ $10^{17} \mathrm{~F} \mathrm{~cm}^{-2}$. Optimum implantation parameters were determined to be between $5 \times 10^{16}$ and $1 \times 10^{17} \mathrm{~F} \mathrm{~cm}^{-2}$. These fluences correspond to maximal F-contents of $10-18$ at.\%, as can be seen from fig. 34. At distinctly higher fluences the external alumina partly tends to the formation of an internal alumina scale. 


\subsubsection{Long time stability of the F-effect at Ni-base superalloys}

The TGA-measurements illustrated in fig. 37 show the mass gain during long term oxidation. The TGA measurements were carried out at $1050^{\circ} \mathrm{C}$ for 1000 hours at samples of IN738 implanted with fluences of $5 \times 10^{16}, 1 \times 10^{17}$ and $2 \times 10^{17} \mathrm{~F} \mathrm{~cm}^{-2} / 38 \mathrm{keV}$. Within the first $50-100$ hours all samples reveal a distinct mass gain. The non-implanted sample is characterized by following a nearly linear mass loss within the whole oxidation time. The sample implanted with $2 \times 10^{17} \mathrm{~F} \mathrm{~cm}^{-2}$ shows a parabolic mass gain but it did not reach slow growth kinetics. After implantation with a fluence of $1 \times 10^{17} \mathrm{~F} \mathrm{~cm}^{-2}$ the parabolic mass gain reaches a slow growth rate after 400 hours, but after 600 hours a slow mass loss is obtained. After implanting with a fluence of $5 \times 10^{16} \mathrm{~F} \mathrm{~cm}^{-2}$ the parabolic behaviour after 200 hours can be characterized by a kinetic constant of $\mathrm{k}_{\mathrm{p}}=2.51 \times 10^{-9} \mathrm{~g}^{2} \mathrm{~cm}^{-4} \mathrm{~h}^{-1}$. After 900 hours a small mass loss occurs. Generally the results of the TGA curves can be influenced by several processes as formation of transient oxides, internal oxidation and nitridation, scale spallation and loss of gaseous Cr-species. The high mass gain during the first $100 \mathrm{~h}$ may be due to the formation of metastable transient oxides. The mass loss is most probably caused by the spallation of an outer chromia or spinel scale and/or the evaporation of Cr-based gaseous species. In order to reveal at least the final scale structure metallographic crosssections were prepared after the TGA-measurements.

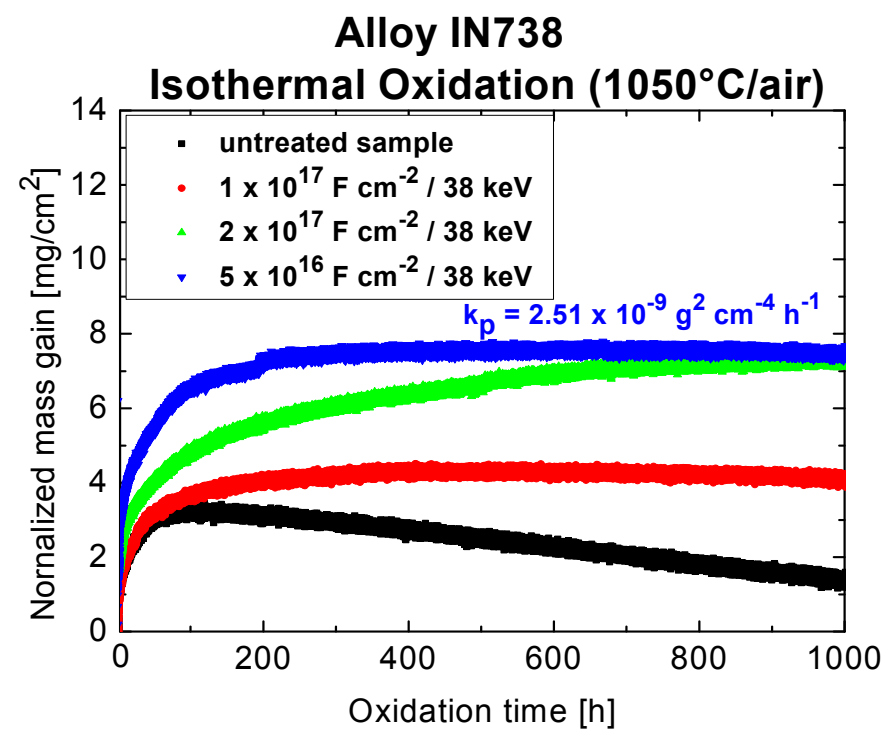

Fig. 37. Isothermal TGA-Measurements at $1050^{\circ} \mathrm{C} /$ air of F-implanted Ni-base alloy IN738.

The metallographic cross-section of the untreated sample (fig. 38, left micrograph) shows a thin scale $(2-3 \mu \mathrm{m})$ of inward growing and non-protective alumina with a thin $(1-2 \mu \mathrm{m})$ spinel layer on top whereas the outer part of the originally formed thick oxide scale had spalled completely. Underneath the alumina scale a large zone of about $30-40 \mu \mathrm{m}$ thickness enriched with nitrides was formed.

A 1-2 $\mu \mathrm{m}$ thin alumina scale covered with a spinel $(1-3 \mu \mathrm{m})$ phase was found on the surface of the sample implanted with $5 \times 10^{16} \mathrm{~F} \mathrm{~cm}^{-2}$ (fig. 38, right micrograph). The absence of $\mathrm{Al}_{2} \mathrm{O}_{3}$ 
- precipitates indicates a change from internal oxidation to the formation of a continuous protective external $\mathrm{Al}_{2} \mathrm{O}_{3}$ - scale. EDX-analysis proofs the composition of this scale as pure alumina, whereas the spinel scale mainly contains $\mathrm{Al}$ and $\mathrm{Ni}$.
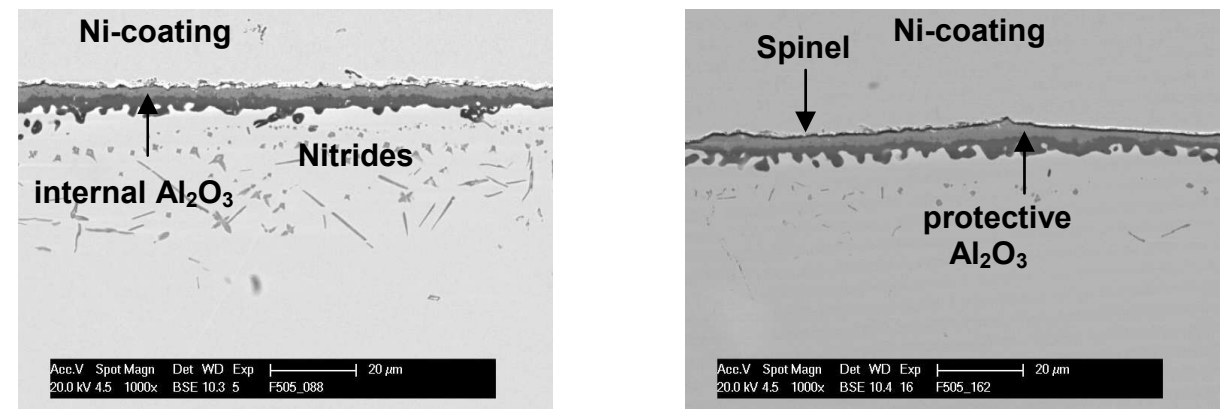

Fig. 38. Oxide scale of an untreated (left micrograph) and an implanted $\left(5 \times 10^{16} \mathrm{~F} \mathrm{~cm}^{-2} / 38\right.$ $\mathrm{keV}$ ) sample (right micrograph) of IN738 after oxidation (TGA/1000h/1050 ${ }^{\circ} \mathrm{C} /$ air).

Finally the region for a positive F-effect for the Ni-base alloy IN738 in terms of F-partial pressures, F-fluences and F-concentrations can be illustrated in fig. 39. In practice there are no sharp boundaries for fluences and concentrations. This is illustrated by the light grey regions.

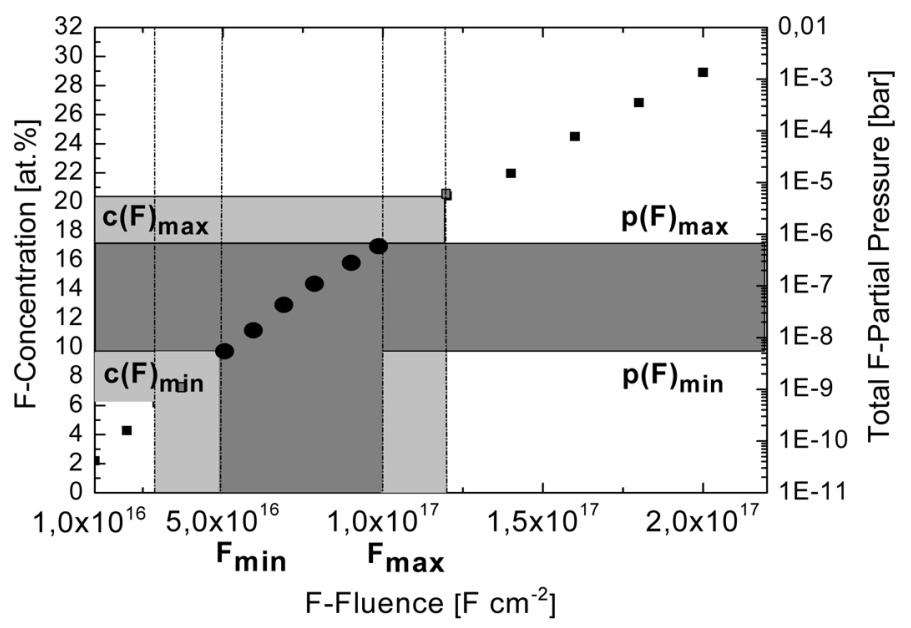

Fig. 39. Relation between F-partial pressures, F-fluences and F-concentrations for a positive F-effect at the Ni-base alloy IN738.

\section{Conclusions}

The ion implantation of fluorine combined with the non-destructive Ion Beam Analysis have been applied to investigate the halogen effect for fluorine at $\gamma$-TiAl and Ni-base alloys. By suitable surface doping of $\mathrm{\gamma}$-TiAl $(44-50$ at.\% $\mathrm{Al})$ with fluorine the high temperature oxidation resistance above $750^{\circ} \mathrm{C}$ has been improved dramatically by stimulating the formation of a dense protective alumina scale on the metal surface. The optimal F- 
concentrations have been defined. Recently these results have been used to apply other methods of F-application (gas phase, liquid phase, plasma immersion ion implantation) for the treatment of technical components with a complex geometry. Based on the results of the beam line ion implantation the optimal parameters can be found also for each of these process routes. The ion beam analysis, especially PIGE, plays an important role in these investigations. The fluorine effect at TiAl-alloys is close to industrial application in high temperature technology.

The Ni-base superalloys with 2-5 wt.\% Al-content form a non-protective complex oxide scale during oxidation at temperatures above $900^{\circ} \mathrm{C}$. After surface modification by fluorine ion implantation the oxidation mechanism can be changed dramatically to the growth of a dense protective alumina scale. Optimal F-concentrations for the F-effect for $1^{\text {st }}$ and $2^{\text {nd }}$ generation Ni-base superalloys have been determined. Recently basic work is in progress to apply the halogen effect to the $3^{\text {rd }}$ and $4^{\text {th }}$ generation superalloys and to improve the scale adherence. Additional studies focuse on the mechanism of the initial oxidation in the presence of the fluorine effect.

\section{Acknowledgment}

The work consisting of several projects was supported to a large extent by the Deutsche Forschungsgemeinschaft (DFG) under contracts SCHU 729/12, SCHU 729/15-1, SCHU 729/18-1 and SCH 729/18-2 which is gratefully acknowledged.

The authors thank Prof. K. Bethge, Dr. H. Baumann, Prof. R. Dörner, Dr. L. Schmidt, Dr. K.E. Stiebing and S. Neve from the Institute of Nuclear Physics of the Goethe-University Frankfurt for their support by using the implanter and the Van de Graaff accelerator.

\section{References}

Biersack, J. (1999). TRIM-DYNAMIC applied to marker broadening and SIMS dept profiling. Nucl. Instr. \& Meth. Phys.. Res. B, 153, (1999), pp. 398-409.

Calphad, www.calphad.com.

Donchev, A.; Gleeson, B. \& Schütze, M. (2003). Thermodynamic considerations of the beneficial effect of halogens on the oxidation resistance of TiAl-based alloys. Intermetallics, 11, (2003), pp. 387-398.

Donchev, A.; Schütze, M.; Heller, J. \& Scheydecker, M. (2006). Oxidationsschutz für Titanaluminidbauteile durch Oberflächenbehandlung mit Fluor. Proceedings Oberflächentage 2006.

FactSage Version 4.5.1 Fa. GTT, Herzogenrath.

Fergus, J. W. (2002). Review of the effect of alloy composition on the growth rates of scales formed during oxidation of gamma titanium aluminide alloys. Materials Science and Engineering, A338, (2002), pp. 108-125.

Hornauer, U,; Richter, E.; Wieser, E.; Möller, W.; Schumacher, G.; Lang, C. \& Schütze, M. (1999). Improvement of the High Temperature Oxidation Resistance of Ti50Al via Ion-Implantation. Nucl. Instr. E Meth. in Phys. Res. B, 148, (1999), pp. 858-862.

Kofstad, P. (1988). High Temperature Oxidation of Metals, Elsevier, New York, 1988.

Kumagai, M.; Shibue, K.; Kim, M.-S. \& Yonemitsu. M. (1996). Influence of chlorine on the oxidation behavior of TiAl-Mn intermetallic compound. Intermetallics, 4, (1996), pp. 557-566. 
Litz., J.; Rahmel, A.; Schorr, M. \& Weiss, J. (1989). Scale Formation on the Ni-Base Superalloys IN 939 and IN 738 LC. Oxidation of Metals, 32, (1989), pp. 167-184.

Masset, P.J. \& Schütze, M. (2008). Thermodynamic Assesments of the Alloy Concentration Limits for the Halogen Effect of TiAl Alloys. Adv. Engin. Mat., 10, 7, (2008), pp. 666- 674.

Nickel, H.; Clemens, D.; Quadakkers, W.J. \& Singheiser, L. (1999). Development of NiCrAlY Alloys for Corrosion-Resistant Coatings and Thermal Barrier Coatings of Gas Turbine Components. Transactions of the ASME, Journal of Pressure Vessel Technology, 121, (1999), pp. 384-387.

Philibert, J. (1990). Diffusion et transport de matiere dans les solides, Les Ulis, 1990.

Pint, B. A.; DiStefano, J. R. \& I. G. Wright (2006). Oxidation resistance: One barrier to moving beyond Ni-base superalloys. Materials Science and Engineering: A, 415, Issues 1-2, (15 January 2006), pp. 255-263.

Rahmel, A.; Quadakkers, W. J. \& Schütze, M. (1995). Fundamentals of TiAl Oxidation - A Critical Review. Materials and Corrossion, 46, (1995), pp. 271-285.

Schütze, M. \& Hald, M. (1997). Improvement of the oxidation resistance of TiAl alloys by using the chlorine effect. Mat. Sci. Eng., A239-240, (1997), pp. 847-858.

Schumacher, G.; Dettenwanger, F.; Schütze, M.; Hornauer, U.; Richter, E.; Wieser, E. \& Möller, W. (1999a). Microalloying Effects in the Oxidation of TiAl Materials. Intermetallics, 7, (1999), pp. 1113-1120.

Schumacher, G.; Lang, C.; Schütze, M.; Hornauer, U.; Richter, E.; Wieser, E. \& Möller, W. (1999b). Improvement of the Oxidation Resistance of gamma titanium aluminides by microalloying with chlorine using ion implantation. Maerials and Corrosion, 50, (1999), 162-165.

Tesmer, J. R. \& Nastasi, M. (1995.), Handbook of Modern Ion Beam Materials Analysis, Materials Research Society, Pittsburgh 1995, PA, USA.

Ziegler, J.; Biersack, J. \& Littmark, U. (1995). The stopping and range of ions in solids, Version 95, 1995, Pergamon Press, New York.

Zschau, H.-E.; Gauthier, V.; Schütze,, M.; Baumann, H. \& Bethge, K. (2002). Investigation of the Fluorine Microalloying Effect in the Oxidation of TiAl at $900^{\circ} \mathrm{C}$ in Air. Proc. International Symposium Turbomat, June 17-19, 2002, Bonn, ed. W. Kaysser, (2002), pp. 210-214.

Zschau, H.-E.; Schütze, M.; Baumann, H. \& Bethge, K. (2005). Application of Ion Beam Analysis for the Control of the Improvement of the Oxidation Resistance of TiAl at $900^{\circ} \mathrm{C}$ in Air by Fluorine Ion Implantation and HF-Treatment. Nucl. Instr. \& Meth. in Phys. Res. B, 240, (2005), pp. 137-141.

Zschau, H.-E.; Schütze, M.; Baumann. H. \& Bethge, K. (2007). Surface modification of titanium aluminides with fluorine to improve their application for high temperature service conditions. Nucl. Instr. \& Meth. in Phys. Res. B, 257, (2007), pp. 383-387.

Zschau, H.-E. \& Schütze, M. (2008). Modelling of the long time stability of the fluorine effect in TiAl oxidation. Materials and Corrosion, 59, 7, (2008), pp. 619-623.

Zschau; H.-E.; Renusch, D.; Masset, P. \& and Schütze, M. (2009a). A new concept of oxidation protection of Ni-base alloys by using the halogen effect. Materials at High Temperatures, 26, No. 1, (2009), pp. 85-89.

Zschau, H.-E.; Masset, P. J.; Renusch, D. \& Schütze, M. (2009b). Thermodynamical Considerations for applying the Halogen Effect to Ni-Base Superalloys. Proc. TMS Spring Meeting, San Francisco, 15.-19.2.2009, pp. 149-156.

Zschau, H.-E.; Renusch, D.; Masset, P. \& Schütze, M. (2009c). The halogen effect for Ni-base alloys - a new method for increasing the oxidation protection at high temperatures. Nucl. Instr. \& Meth. in Phys. Res. B, 267, Issue 8-9, (2009), pp. 1662-1665. 


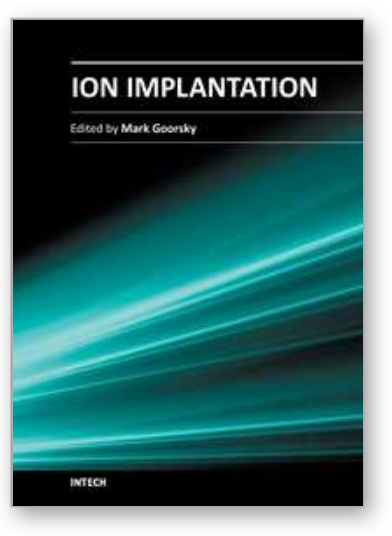

\author{
Ion Implantation \\ Edited by Prof. Mark Goorsky
}

ISBN 978-953-51-0634-0

Hard cover, 436 pages

Publisher InTech

Published online 30, May, 2012

Published in print edition May, 2012

Ion implantation presents a continuously evolving technology. While the benefits of ion implantation are well recognized for many commercial endeavors, there have been recent developments in this field. Improvements in equipment, understanding of beam-solid interactions, applications to new materials, improved characterization techniques, and more recent developments to use implantation for nanostructure formation point to new directions for ion implantation and are presented in this book.

\title{
How to reference
}

In order to correctly reference this scholarly work, feel free to copy and paste the following:

Hans-Eberhard Zschau and Michael Schütze (2012). Surface Modification by Ion Implantation to Improve the Oxidation Resistance of Materials for High Temperature Technology, Ion Implantation, Prof. Mark Goorsky (Ed.), ISBN: 978-953-51-0634-0, InTech, Available from: http://www.intechopen.com/books/ionimplantation/surface-modification-by-ion-implantation-to-improve-the-oxidation-resistance-of-materials-for-hi

\section{INTECH}

open science | open minds

\author{
InTech Europe \\ University Campus STeP Ri \\ Slavka Krautzeka 83/A \\ 51000 Rijeka, Croatia \\ Phone: +385 (51) 770447 \\ Fax: +385 (51) 686166 \\ www.intechopen.com
}

\author{
InTech China \\ Unit 405, Office Block, Hotel Equatorial Shanghai \\ No.65, Yan An Road (West), Shanghai, 200040, China \\ 中国上海市延安西路65号上海国际贵都大饭店办公楼 405 单元 \\ Phone: +86-21-62489820 \\ Fax: $+86-21-62489821$
}


(C) 2012 The Author(s). Licensee IntechOpen. This is an open access article distributed under the terms of the Creative Commons Attribution 3.0 License, which permits unrestricted use, distribution, and reproduction in any medium, provided the original work is properly cited. 